\title{
A Spatial Coupling Model to Study Dynamic Performance of Pantograph-catenary with Vehicle-track Excitation
}

In the high-speed railway industry, the pantograph-catenary system is responsible to provide continuous electric energy for the high-speed train. The pantographcatenary system suffers multiple impacts from the complex work environment. The vehicle-track excitation is one of the normal disturbances to the pantographcatenary interaction. Previous studies only consider the vertical effect of the vehicle-track vibration on the pantograph-catenary interaction. To address this deficiency, both of the pantograph-catenary and vehicle-track models are constructed in this paper. The validations of both models are verified by the experimental test and the world benchmark, respectively. The pantograph base follows the translations and rotations of the car-body caused by random rail irregularities. In combination with a spatial contact model between the contact wire and the pantograph strip, the spatial vibration of the carbody can be fully considered in the pantograph-catenary interaction. The statistical analysis, stochastic analysis and frequency analysis are performed to make sense of the effect of the random track irregularities on the pantograph-catenary interaction. The deviation of the contact point away from the strip centre caused by the carbody vibration is also analysed. The results show that the reliability of the pantographcatenary system shows a continuous decrease in the degradation of rail quality. The carbody vibration may cause the de-wirement of the pantograph in extreme conditions. Finally, an application example is given to evaluate the dynamic performance of the pantograph-catenary system running on the China high-speed network with realistic rail irregularities.

Keywords: High-Speed Railway; Vehicle-track interaction; Pantograph-Catenary Interaction; Contact force; Dynamic performance; Rail irregularities

\section{Nomenclature}

$\begin{array}{ll}\text { Attribute } & \text { Description } \\ l_{\mathrm{e}} & \text { Element length of the rail } \\ m_{\mathrm{r}}, A_{\mathrm{r}} & \text { Linear mass and cross-section area of the rail } \\ h_{\mathrm{s}}, b_{\mathrm{s}}, l_{\mathrm{s}} & \text { Height, width and length of the slab in one track element }\end{array}$




\begin{tabular}{|c|c|}
\hline$W_{\mathrm{r}}$ & Polar moment of inertial of the rail cross-section \\
\hline$m_{\mathrm{s}}$ & Mass of the slab per unit volume \\
\hline$E_{\mathrm{r}}$ & Young's Modulus of the rail \\
\hline$I_{\mathrm{ry}}, I_{\mathrm{rz}}$ & Moment of inertia around $\mathrm{Y}$ - and $\mathrm{Z}$ - axis \\
\hline$G_{\mathrm{rt}}$ & Rigidity modulus of the rail \\
\hline$I_{\mathrm{rt}}$ & Torsion constant for the rail section \\
\hline$E_{\mathrm{s}}$ & Young's Modulus of the slab \\
\hline$\mu_{\mathrm{s}}$ & Poisson rate of the slab \\
\hline$k_{\mathrm{rs}}^{y}, k_{\mathrm{rs}}^{z}$ & The lateral and vertical stiffness of the rail pad \\
\hline$k_{\mathrm{sd}}^{y}, k_{\mathrm{sd}}^{z}$ & The lateral and vertical stiffness of the CA Mortar \\
\hline$c_{\mathrm{rs}}^{y}, c_{\mathrm{rs}}^{z}$ & The lateral and vertical damping of the rail pad \\
\hline$c_{\mathrm{sd}}^{z}, c_{\mathrm{sd}}^{y}$ & The lateral and vertical damping of the CA Mortar \\
\hline$G$ & Hertzian wheel-rail constant coefficient \\
\hline$\delta Z_{\mathrm{VT}}(t)$ & The penetration of contact surface between wheels and rail \\
\hline$l_{\mathrm{x}}, l_{\mathrm{y}}, l_{\mathrm{z}}$ & Relative distances between two nodes of cable element in $x$-, $y$ - and $z$ - axis \\
\hline$l_{0}$ & Unstrained length of cable element \\
\hline$f_{1}, f_{2}, f_{3}$ & Nodal force on the node I of cable element in $x$ -,$y$ - and $z$ - axis \\
\hline$f_{4}, f_{5}, f_{6}$ & Nodal force on the node $\mathrm{J}$ of cable element in $x-, y$ - and $z$ - axis \\
\hline$E_{\mathrm{c}}$ & Young's Modulus of the cable element \\
\hline$A_{\mathrm{c}}$ & Cross-section area of the cable element \\
\hline$w_{\mathrm{c}}$ & Self-weight of the cable element \\
\hline$l_{\mathrm{gx}}, l_{\mathrm{gy}}, l_{\mathrm{gz}}$ & $\begin{array}{l}\text { Relative distances between two nodes of truss element in } x_{\mathrm{g}^{-}}, y_{\mathrm{g}^{-}} \text {and } z_{\mathrm{g}^{-}} \\
\text {axis }\end{array}$ \\
\hline$l_{\mathrm{g} 0}$ & Unstrained length of truss element \\
\hline$f_{\mathrm{g} 1}, f_{\mathrm{g} 2}, f_{\mathrm{g} 3}$ & Nodal force on the node I of truss element in $x-, y$ - and $z$ - axis \\
\hline$f_{\mathrm{g} 4}, f_{\mathrm{g} 5}, f_{\mathrm{g} 6}$ & Nodal force on the node $\mathrm{J}$ of truss element in $x$-, $y$ - and $z$ - axis \\
\hline$E_{\mathrm{g}}$ & Young's Modulus of the dropper \\
\hline$A_{\mathrm{g}}$ & Cross-section area of the dropper \\
\hline
\end{tabular}




$\begin{array}{ll}m_{\mathrm{p} 1}, m_{\mathrm{p} 2}, m_{\mathrm{p} 3} & \text { Mass of pantograph head, upper framework and lower framework } \\ k_{\mathrm{p} 1}, k_{\mathrm{p} 2}, k_{\mathrm{p} 3} & \text { Stiffness of pantograph head, upper framework and lower framework } \\ c_{\mathrm{p} 1}, c_{\mathrm{p} 2}, c_{\mathrm{p} 3} & \text { Damping of pantograph head, upper framework and lower framework } \\ K_{\mathrm{c}} & \text { Pantograph-catenary contact stiffness } \\ \delta Z_{\mathrm{pC}}(t) & \text { The penetration of contact surface between pantograph and catenary } \\ \phi_{\mathrm{cb}}, \psi_{\mathrm{cb}}, \beta_{\mathrm{cb}} & \text { The roll, yaw and pitch of carbody } \\ Y_{\mathrm{cb}}, Z_{\mathrm{cb}} & \text { The traverse motion and bounce of carbody } \\ w_{\mathrm{irr}} & \text { Track irregularity } \\ a_{\mathrm{irr}}, l_{\mathrm{irr}} & \text { Track irregularity amplitude and wavelength } \\ A_{\mathrm{v}}, A_{\mathrm{a}}, A_{\mathrm{c}}, A_{\mathrm{g}} & \begin{array}{l}\text { Roughness coefficients for profile, alignment, crosslevel and gage rail } \\ \phi_{\mathrm{v}}, \phi_{\mathrm{a}}, \phi_{\mathrm{c}}, \phi_{\mathrm{g}}\end{array} \\ S_{\mathrm{v}}, S_{\mathrm{a}}, S_{\mathrm{c}}, S_{\mathrm{g}} & \begin{array}{l}\text { Cutregularities frequencies for profile, alignment, crosslevel and gage rail } \\ \text { irregularities }\end{array} \\ P_{\mathrm{R}} & \text { PSDs for profile, alignment, crosslevel and gage rail irregularities }\end{array}$

\section{Introduction}

In recent years, the impressive expansion of the high-speed network mileage around the world is the significant reflection of the global tendency towards the incremental demand of high-speed railway from all the aspects of economy and society [1]. The fundamental research on the dynamics of coupled systems in high-speed railway attracts everincreasing attention from the industrial and the academic communities, as they are main factors to keep the safe and reliable operation of high-speed railway, as well as determine the maximum speed of high-speed train [2]. Due to the complexity of the high-speed railway system, many independent relationships exist among the train [3], the electrical equipment [4], the infrastructure [5] and the environment [6], which interact, depend upon and restrict each other. The most significant examples are the vehicle-track interaction [7], the pantograph-catenary interaction [8], the fluid-solid interaction [9] and the 
electromechanical coupling [10]. Among them, the pantograph-catenary system is the only source of power for electric trains. As shown in Figure 1, the catenary constructed along the railroad is responsible for transmitting the electric energy to the locomotive through the sliding contact with the pantograph installed on the locomotive. Due to its complex work environment [11], the pantograph-catenary system suffers multiple excitations from the vehicle-track vibration [12], the component defects $[13,14]$, the contact wire irregularities [15] and the wind load [16], which make the pantographcatenary to be the most venerable part in the traction power system. According to the previous studies, the wind load primarily affects the pantograph-catenary interaction only in extreme conditions [17]. The component defect of the catenary occurs intermittently [18]. Only the vehicle-track vibration has a continuous effect on the pantograph-catenary interaction.

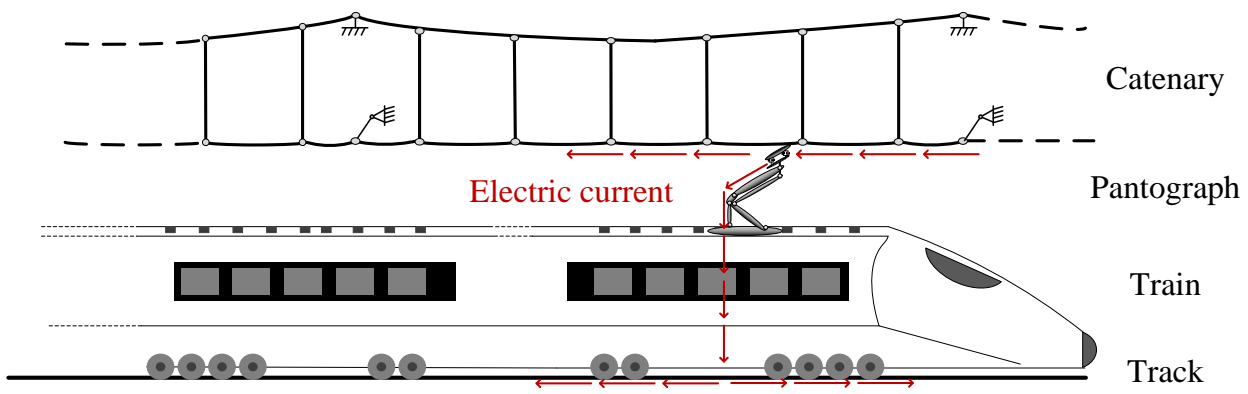

Figure 1. Pantograph-catenary-vehicle-track system

Generally, the quality of current collection for a high-speed train is directly represented by the contact force between the strip of the pantograph and the contact wire of the catenary [19]. An excessive contact force is able to aggravate the wear and fatigue of the contact wire and the strip [20], while an inadequate contact force may increase the possibility of the contact loss between the pantograph and the catenary. Once the contact loss occurs, the arcing and sparking between the contact wire and the strip cause the sudden increase of the temperature, which may result in the erosion and liquation of the 
contact surface [21]. Sometimes, the contact loss may even cause the interruption of the electrical transmission to the train. In order to ensure stable contact between the pantograph and the catenary, various pantograph-catenary models are proposed to make sense of the complex coupling dynamics of the pantograph-catenary system [22]. The catenary modelling methodology has experienced a long-term evolvement from the simple lumped-parameter model [23] to the increasingly complicated distributedparameter model [24]. The pantograph is normally modelled by three or two masses connected by equivalent springs and dampers, as it is an efficient representation for the physical characteristics. Some researchers attempt to develop advanced multi-body models for pantographs [25-27], which have better capabilities to describe the realistic behaviours. Employing advanced numerical methods, the efficiencies of simulation models are considerably improved [28-30]. The accuracies of the proposed models are verified by comparisons with experimental data from laboratory [31-33] and field tests [34-36]. Based on the simulation results, some effective strategies are proposed to improve the quality of current collection, such as tuning the contact wire tension [37], optimising pantograph interval [38], adjusting the suspension parameters of pantograph [39] and employing an active pantograph with dampers [40] or controllers [41-44] etc. As the ever-increasing understanding of the pantograph-catenary dynamics, more attentions are paid to optimise the wave propagation behaviour [45] and the elasticity distribution [46] along the contact wire. Considering the realistic work condition, the dynamic interaction between the pantograph and the catenary is always affected by complex external perturbations. In [47,48], the wind field along the catenary is established to analyse its effect on the contact force. The aerodynamics on the pantograph is quantified through the computational fluid dynamics [49], the wind tunnel experiment [50] and the field test [51]. As for the effect of vehicle-track excitation, it is worthwhile 
to mention the works of Zhai et al [52] and Carnicero et al [53]. In Zhai's work, a multibody pantograph model is established. The carbody acceleration is exerted on the bottom of the pantograph to simulate the vertical effect of the vehicle-track vibration on the pantograph-catenary interaction. The results show that the large-amplitude rail irregularities have a non-negligible effect on the contact force of pantograph-catenary. Carnicero et al employ the Lagrange multiplier method to couple the vehicle-track and the pantograph-catenary. The contact force of the pantograph-catenary is analysed with different levels of random rail irregularities. The results show that the quality of current collection deteriorates significantly with the degradation of the track quality.

However, in these two works, only the vertical effect of the vehicle-track excitation on the pantograph-catenary interaction is considered. In reality, the rail irregularities, cross-wind [54] and flexibility [55] cause the motion of the car-body with six degrees of freedom (DOFs). Except for the vertical translation, the pitch and roll of the car-body definitely cause the vertical movement of the pantograph bottom [56], which thus brings more disturbance to the contact force of the pantograph-catenary. Furthermore, the lateral translation, yaw and roll of the car-body may cause the variance of the contact point position on the pantograph strip, which deserves further analysis to avoid the pantograph de-wiring from the contact wire. In this paper, the shortfalls in previous studies are addressed. A spatial model to couple the pantograph-catenary and the vehicle-track is proposed. As the mass and stiffness of the pantograph are some orders of magnitude smaller than the car-body and the suspensions in the vehicle, the effect of the pantograph-catenary on the vehicle dynamics is totally negligible. Based on this assumption, a methodology is proposed to make the pantograph base follow the movement of the carbody. In combination with a spatial contact model between the contact wire and the pantograph strip, the spatial vibration of the vehicle can be fully 
considered in the pantograph-catenary interaction. The statistical analysis, stochastic analysis, and frequency analysis are performed to make sense of the effect of the random track irregularities on the pantograph-catenary interaction. The deviation of the contact point away from the strip centre caused by the carbody vibration is also analysed. The full paper is organized by seven sections. The introduction of the background and the literature review are in Section I. The spatial vehicle-track model is described in Section II. The pantograph-catenary model is described in Section III. The coupling method of two models is present in Section IV. The stochastic analysis with random track irregularities is performed in Section V. Section VI reports an application example using realistic parameters from the China high-speed network. The conclusions and future works are drawn in Section VII.

\section{Vehicle-track formulations}

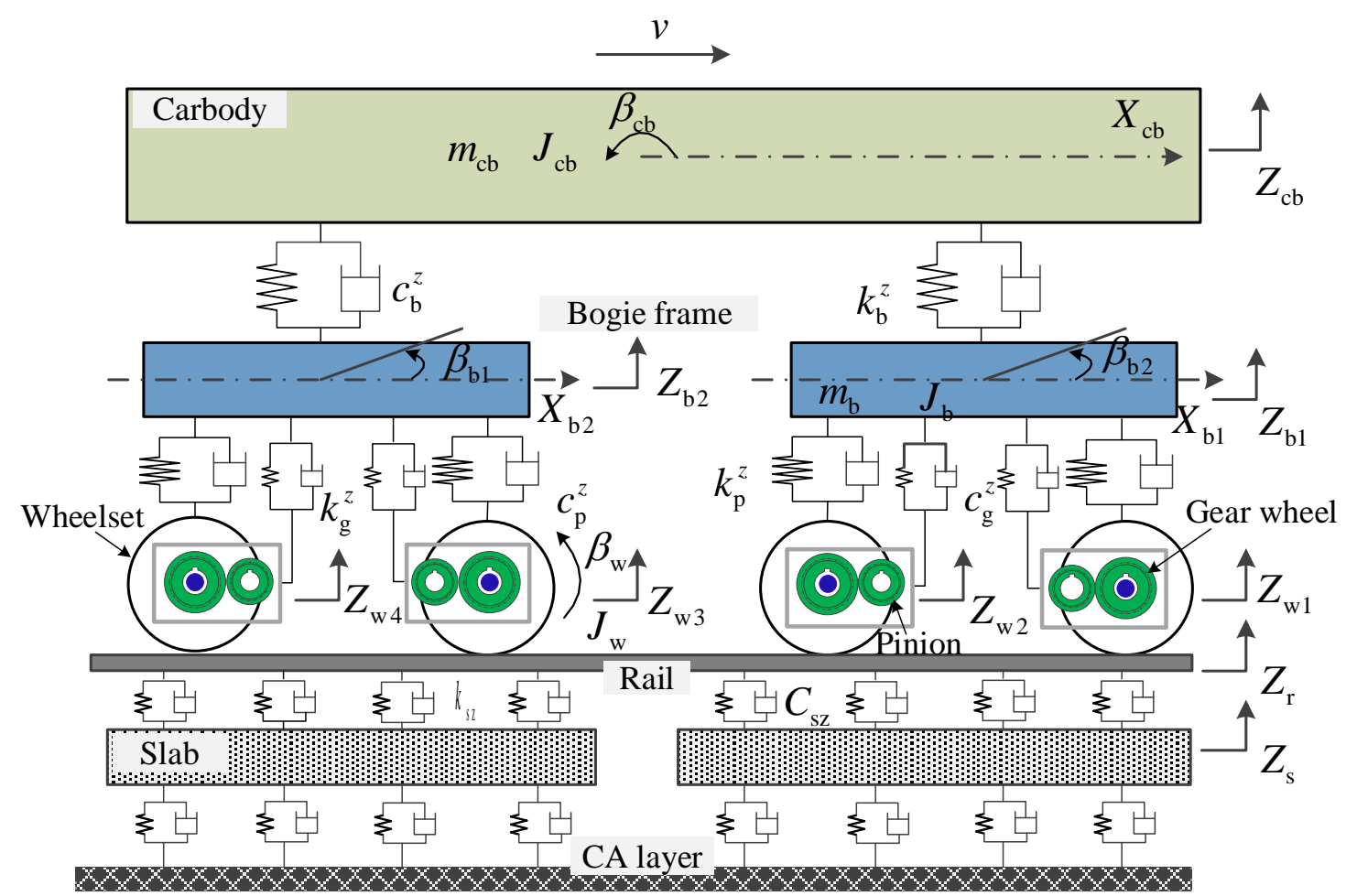

Figure 2. Vehicle-track coupled dynamics model (elevation view) 
In this paper, a classic three-dimensional vehicle-track model is established to simulate the spatial motion of the car-body. Figure 2 and Figure 3 show the schematics of the vehicle-track model from the elevation and end views, respectively. The lumped parameters in Figures 2-3 are adopted from [57], which presents a widely used reference model for the academic community.

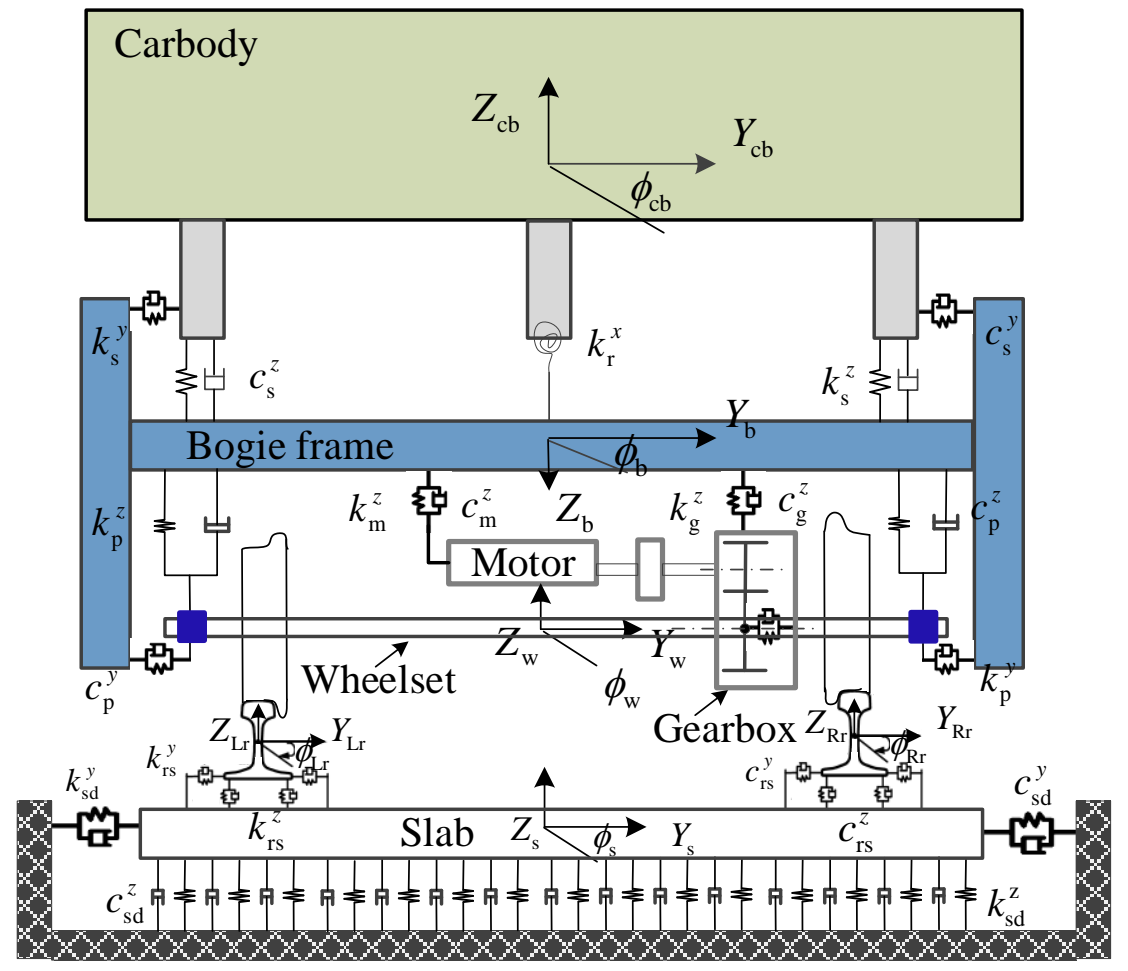

Figure 3. Vehicle-track coupled dynamics model (end view)

\subsection{Vehicle model}

The vehicle model is comprised of a carbody, two bogies, four traction transmission systems (traction motor and gear box), four wheelsets and two stage suspensions. All these components are modelled by multi rigid-bodies connected by springs and dampers. Besides, the nonlinear elements, such as the lateral damper, lateral stopper and yaw dampers, are also considered. Apart from the traction transmission systems, each of them has 5 DOFs, including traverse motion $Y$, bounce $Z$, roll $\phi$, yaw $\psi$ and pitch $\beta$, with 
respect to its mass centroid. Thus, the vehicle has totally 19 rigid bodies with 53 DOFs, as shown in Figure 3. Based on the multibody dynamics, the equation of motion for the vehicle can be written by

$$
\mathrm{M}_{\mathrm{V}} \ddot{\mathbf{U}}_{\mathrm{V}}+\mathrm{C}_{\mathrm{V}} \dot{\mathrm{U}}_{\mathrm{V}}+\mathrm{K}_{\mathrm{V}} \mathrm{U}_{\mathrm{V}}=\mathrm{F}_{\mathrm{V}}
$$

where, $\mathbf{M}_{\mathrm{V}}, \mathbf{C}_{\mathrm{V}}$ and $\mathbf{K}_{\mathrm{V}}$ are the mass, damping and stiffness matrices of the vehicle

respectively. $\ddot{\mathbf{U}}_{\mathrm{V}}, \dot{\mathbf{U}}_{\mathrm{V}}$ and $\mathbf{U}_{\mathrm{v}}$ are the acceleration, velocity and displacement vectors of the vehicle respectively. $\mathbf{F}_{\mathrm{V}}$ is the external force vector.

\subsection{Track model}

The track model consists of rails and slabs. The two rails are modelled by Euler-Bernoulli beams supported by slabs. The three-dimensional slabs are described as thin plate elements on viscoelastic foundations. According to the finite element method, the equation of motion for the track can be written by

$$
\mathbf{M}_{\mathrm{T}} \ddot{\mathbf{U}}_{\mathrm{T}}+\mathbf{C}_{\mathrm{T}} \dot{\mathbf{U}}_{\mathrm{T}}+\mathbf{K}_{\mathrm{T}} \mathbf{U}_{\mathrm{T}}=\mathbf{F}_{\mathrm{T}}
$$

in which, $\ddot{\mathbf{U}}_{\mathrm{T}}, \dot{\mathbf{U}}_{\mathrm{T}}$ and $\mathbf{U}_{\mathrm{T}}$ are the global acceleration, velocity and displacement vectors of the track respectively. $\mathbf{F}_{\mathrm{T}}$ is the external force vector applied on the track. The mass matrix $\mathbf{M}_{\mathrm{T}}$, the damping matrix $\mathbf{C}_{\mathrm{T}}$ and the stiffness matrix $\mathbf{K}_{\mathrm{T}}$ can be assembled by the element matrix $\mathbf{M}_{\mathrm{t}, n}^{\mathrm{e}}, \mathbf{C}_{\mathrm{t}, n}^{\mathrm{e}}$ and $\mathbf{K}_{\mathrm{t}, n}^{\mathrm{e}}$ of the $n^{\text {th }}$ track segment as follows:

$$
\mathbf{M}_{\mathrm{T}}=\sum_{n} \mathbf{M}_{\mathrm{t}, n}^{\mathrm{e}}, \mathbf{C}_{\mathrm{T}}=\sum_{n} \mathbf{C}_{\mathrm{t}, n}^{\mathrm{e}}, \mathbf{K}_{\mathrm{T}}=\sum_{n} \mathbf{K}_{\mathrm{t}, n}^{\mathrm{e}}
$$

Considering a consistent mass matrix, $\mathbf{M}_{\mathrm{t}, n}^{\mathrm{e}}$ can be calculated by

$$
\mathbf{M}_{\mathrm{t}, n}^{\mathrm{e}}=\mathbf{M}_{\mathrm{r}, n}^{\mathrm{e}}+\mathbf{M}_{\mathrm{s}, n}^{\mathrm{e}}
$$

in which, $\mathbf{M}_{\mathrm{r}, n}^{\mathrm{e}}$ and $\mathbf{M}_{\mathrm{s}, n}^{\mathrm{e}}$ denote the mass matrices of the rail and the slab, respectively, which are expressed by [54] 


$$
\begin{aligned}
\mathbf{M}_{\mathrm{r}, n}^{\mathrm{e}}= & \sum m_{\mathrm{r}} \int_{0}^{l_{\mathrm{e}}} \mathbf{N}_{x}^{\mathrm{rT}} \mathbf{N}_{x}^{\mathrm{r}} \mathrm{d} x+m_{\mathrm{r}} \int_{0}^{l_{\mathrm{e}}} \mathbf{N}_{y}^{\mathrm{r} T} \mathbf{N}_{y}^{\mathrm{r}} \mathrm{d} x+m_{\mathrm{r}} \int_{0}^{l_{\mathrm{e}}} \mathbf{N}_{z}^{\mathrm{rT}} \mathbf{N}_{z}^{\mathrm{r}} \mathrm{d} x \\
& +\frac{m_{\mathrm{r}}}{A_{\mathrm{r}}} W_{\mathrm{r}} \int_{0}^{l_{\mathrm{e}}} \mathbf{N}_{\theta x}^{\mathrm{r}} \mathbf{N}_{\theta x}^{\mathrm{r}} \mathrm{d} x \\
\mathbf{M}_{\mathrm{s}, n}^{\mathrm{e}}= & m_{\mathrm{s}} h_{\mathrm{s}} \int_{-b_{\mathrm{s}} / 2}^{b_{\mathrm{s}} / 2} \int_{0}^{l_{\mathrm{s}}} \mathbf{N}_{z}^{\mathrm{sT}} \mathbf{N}_{z}^{s} \mathrm{~d} x \mathrm{~d} y+m_{\mathrm{s}} h_{\mathrm{s}} b_{\mathrm{s}} \int_{0}^{l_{\mathrm{s}}} \mathbf{N}_{y}^{\mathrm{sT}} \mathbf{N}_{y}^{s} \mathrm{~d} x
\end{aligned}
$$

in which, $\mathbf{N}_{x}^{\mathrm{r}}, \mathbf{N}_{y}^{\mathrm{r}}, \mathbf{N}_{z}^{\mathrm{r}}$ and $\mathbf{N}_{\theta x}^{\mathrm{r}}$ are the shape functions of the Bernoulli beam along the $X$-, $Y$ - and $Z$ - axis and around the $X$ - axis, respectively. $\mathbf{N}_{z}^{s}$ and $\mathbf{N}_{y}^{\mathrm{s}}$ are the shape functions of the thin plate element along the $\mathrm{Z}$ - and $\mathrm{Y}$ - axis.

Similarly, the element stiffness matrix $\mathbf{K}_{\mathrm{t}, n}^{\mathrm{e}}$ can be written by

$$
\mathbf{K}_{\mathrm{t}, n}^{\mathrm{e}}=\mathbf{K}_{\mathrm{r}, n}^{\mathrm{e}}+\mathbf{K}_{\mathrm{s}, n}^{\mathrm{e}}+\mathbf{K}_{\mathrm{r}-\mathrm{s}, n}^{\mathrm{e}}+\mathbf{K}_{\mathrm{s}-\mathrm{d}, n}^{\mathrm{e}}
$$

in which, $\mathbf{K}_{\mathrm{r}, n}^{\mathrm{e}}$ and $\mathbf{K}_{\mathrm{s}, n}^{\mathrm{e}}$ are the stiffness matrices of the rail and the slab, respectively. $\mathbf{K}_{\mathrm{r}-\mathrm{s}, n}^{\mathrm{e}}$ describes the interactions between the rail and the track slab through the rail pads. $\mathbf{K}_{\mathrm{s}-\mathrm{d}, n}^{\mathrm{e}}$ describes the interactions between the slab and the subgrade. These stiffness matrices can be expressed by

$$
\begin{aligned}
& \mathbf{K}_{\mathrm{r}, n}^{\mathrm{e}}=\sum E_{\mathrm{r}} A_{\mathrm{r}} \int_{0}^{l_{\mathrm{e}}}\left(\frac{\partial \mathbf{N}_{x}^{\mathrm{r}}}{\partial x}\right)^{\mathrm{T}} \frac{\partial \mathbf{N}_{x}^{\mathrm{r}}}{\partial x} \mathrm{~d} x+E_{\mathrm{r}} I_{\mathrm{ry}} \int_{0}^{l_{\mathrm{e}}}\left(\frac{\partial^{2} \mathbf{N}_{x}^{\mathrm{r}}}{\partial x^{2}}\right)^{\mathrm{T}} \frac{\partial^{2} \mathbf{N}_{x}^{\mathrm{r}}}{\partial x^{2}} \mathrm{~d} x \\
& +E_{\mathrm{r}} I_{\mathrm{rz}} \int_{0}^{l_{\mathrm{e}}}\left(\frac{\partial^{2} \mathbf{N}_{y}^{\mathrm{r}}}{\partial x^{2}}\right)^{\mathrm{T}} \frac{\partial^{2} \mathbf{N}_{y}^{\mathrm{r}}}{\partial x^{2}} \mathrm{~d} x+G_{\mathrm{rt}} I_{\mathrm{rt}} \int_{0}^{l_{\mathrm{e}}}\left(\frac{\partial^{2} \mathbf{N}_{\theta x}^{\mathrm{r}}}{\partial x^{2}}\right)^{\mathrm{T}} \frac{\partial^{2} \mathbf{N}_{\theta x}^{\mathrm{r}}}{\partial x^{2}} \mathrm{~d} x \\
& \mathbf{K}_{\mathrm{s}, n}^{\mathrm{e}}=\int_{-b_{\mathrm{s}} / 2}^{b_{\mathrm{s}} / 2} \int_{-l_{\mathrm{s}} / 2}^{l_{\mathrm{s}} / 2} \mathbf{B}^{\mathrm{T}} \mathbf{D} \mathbf{B} \mathrm{d} x \mathrm{~d} y, \mathbf{B}=-\left[\frac{\partial^{2} \mathbf{N}_{z}^{\mathrm{s}}}{\partial x^{2}} \frac{\partial^{2} \mathbf{N}_{z}^{\mathrm{s}}}{\partial y^{2}} \frac{\partial^{2} \mathbf{N}_{z}^{\mathrm{s}}}{\partial x \partial y}\right]^{\mathrm{T}} \\
& \mathbf{D}=\frac{E_{\mathrm{s}} h_{\mathrm{s}}^{3}}{12\left(1-\mu_{\mathrm{s}}^{2}\right)}\left[\begin{array}{ccc} 
& & \\
1 & \mu_{\mathrm{s}} & 0 \\
\mu_{\mathrm{s}} & 1 & 0 \\
0 & 0 & \frac{\left(1-\mu_{\mathrm{s}}\right)}{2}
\end{array}\right] \\
& \mathbf{K}_{\mathrm{r}-\mathrm{s}, n}^{\mathrm{e}}=\sum\left(k_{\mathrm{rs}}^{y} \Gamma_{\mathrm{rs}, n}^{y}{ }^{\mathrm{T}} \Gamma_{\mathrm{rs}, n}^{y}+k_{\mathrm{rs}}^{z} \Gamma_{\mathrm{rs}, n}^{z}{ }^{\mathrm{T}} \Gamma_{\mathrm{rs}, n}^{z}\right) \\
& \mathbf{K}_{\mathrm{s}-\mathrm{d}, n}^{\mathrm{e}}=\sum\left(k_{\mathrm{sd}}^{z} \int_{-b_{\mathrm{s}} / 2}^{b_{\mathrm{s}} / 2} \int_{-l_{\mathrm{s}} / 2}^{l_{\mathrm{s}} / 2} \mathbf{N}_{z}^{\mathrm{rT}} \mathbf{N}_{z}^{\mathrm{r}} \mathrm{d} x \mathrm{~d} y+k_{\mathrm{sd}}^{y} \int_{0}^{l_{\mathrm{s}}} \mathbf{N}_{y}^{\mathrm{sT}} \mathbf{N}_{y}^{\mathrm{s}} \mathrm{d} x\right)
\end{aligned}
$$

in which, $\Gamma_{\mathrm{rs}, n}^{y}$ and $\Gamma_{\mathrm{rs}, n}^{z}$ are the transform vectors depicting the relative lateral and vertical motions between the rail and the slab, respectively. 
The damping elemental matrix $\mathbf{C}_{\mathrm{t}, n}^{\mathrm{e}}$ can be written by

$$
\mathbf{C}_{\mathrm{t}, n}^{\mathrm{e}}=\mathbf{C}_{\mathrm{r}-\mathrm{s}, n}^{\mathrm{e}}+\mathbf{C}_{\mathrm{s}-\mathrm{d}, n}^{\mathrm{e}}
$$

in which, $\mathbf{C}_{\mathrm{r}-\mathrm{s}, n}^{\mathrm{e}}$ and $\mathbf{C}_{\mathrm{s}-\mathrm{d}, n}^{\mathrm{e}}$ are expressed by

$$
\begin{aligned}
& C_{\mathrm{r}-\mathrm{s}, n}^{\mathrm{e}}=\sum\left(c_{\mathrm{rs}}^{y} \Gamma_{\mathrm{rs}, n}^{y}{ }^{\mathrm{T}} \Gamma_{\mathrm{rs}, n}^{y}+c_{\mathrm{rs}}^{z} \Gamma_{\mathrm{rs}, n}^{z}{ }^{\mathrm{T}} \Gamma_{\mathrm{rs}, n}^{z}\right) \\
& C_{\mathrm{s}-\mathrm{d}, n}^{\mathrm{e}}=\sum\left(c_{\mathrm{sd}}^{z} \int_{-b_{\mathrm{s}} / 2}^{b_{\mathrm{s}} / 2} \int_{-l_{\mathrm{s}} / 2}^{l_{\mathrm{s}} / 2} \mathbf{N}_{z}^{\mathrm{rT}} \mathbf{N}_{z}^{\mathrm{r}} \mathrm{d} x \mathrm{~d} y+c_{\mathrm{sd}}^{y} \int_{0}^{l_{\mathrm{s}}} \mathbf{N}_{y}^{\mathrm{sT}} \mathbf{N}_{y}^{\mathrm{s}} \mathrm{d} x\right)
\end{aligned}
$$

\subsection{Wheel-rail interaction}

The wheel-rail interaction is realised by the nonlinear Hertzian elastic contact theory. The contact force $F_{\mathrm{VT}}(t)$ is calculated by [58]

$$
F_{\mathrm{VT}}(t)= \begin{cases}{\left[\frac{1}{G} \delta Z_{\mathrm{VT}}(t)\right]^{3 / 2}} & \text { if } \delta Z_{\mathrm{VT}}(t)>0 \\ 0 & \text { if } \delta Z_{\mathrm{VT}}(t) \leq 0\end{cases}
$$

The Shen-Hedrick-Elkins model is used to calculate the tangential wheel-rail contact forces, which is an expansion of the Kalker's linear creep theory [59].

\subsection{Verification of Vehicle-track model}

In order to verify the validation of the present vehicle-track model, the field experimental tests are carried out in the China high-speed network [60]. The configurations of the accelerometers on the carbody are shown in Figure 4. The same work conditions are set in the numerical simulation. Figure 5 presents the lateral and vertical accelerations of the carbody in time and frequency domains. It can be seen that the amplitude and the dominant frequency of the simulations show good consistency with the experimental tests. The peaks appearing at $0.9 \mathrm{~Hz}$ and $2.8 \mathrm{~Hz}$ are close to the natural frequencies of the carbody pitch and roll, respectively. Hence, it indicates that the present vehicle-track coupled dynamics model can adequately describe the physical characteristics of the vehicle-track system. 


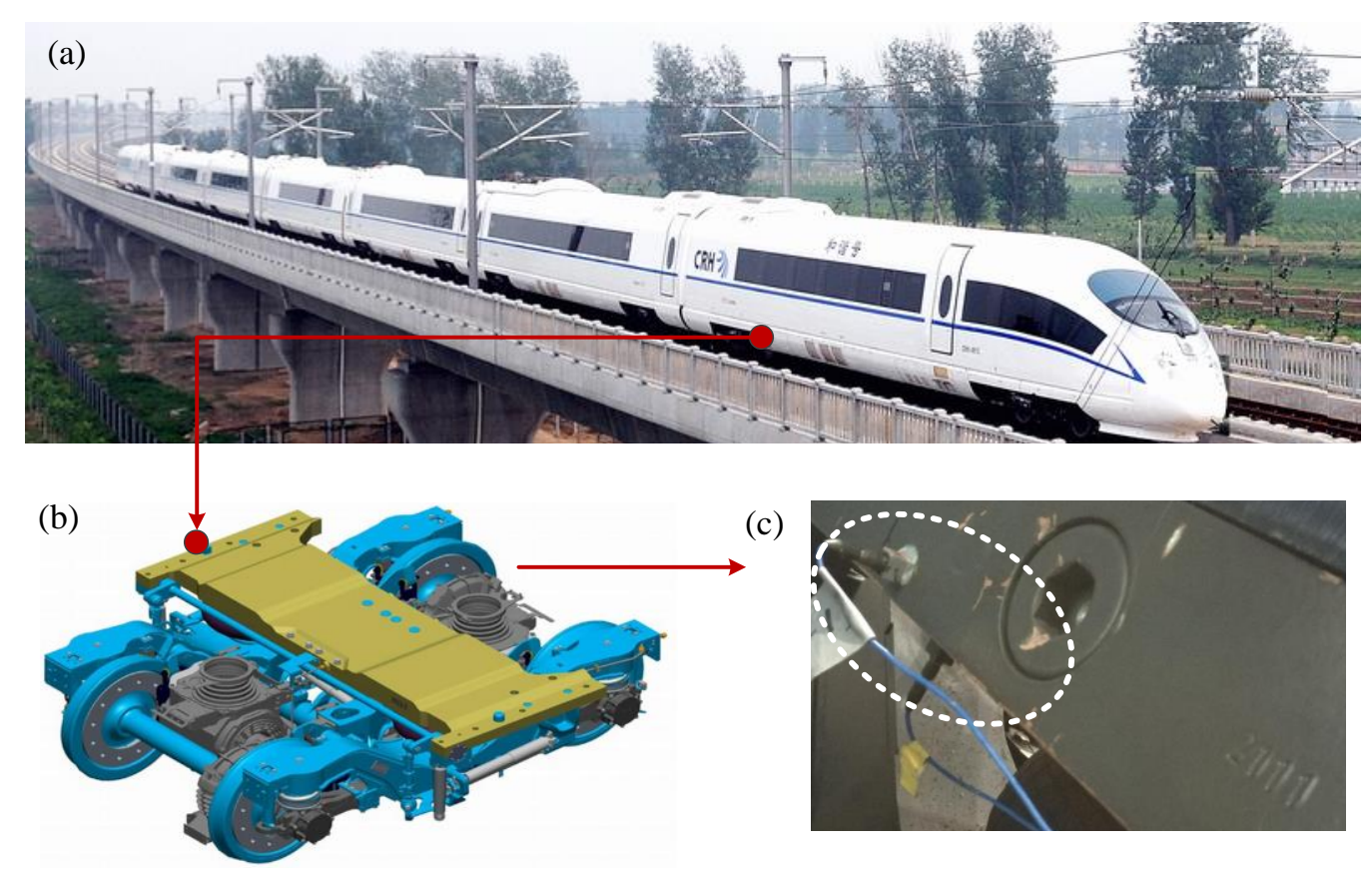

Figure 4. Configurations of sensors on carbody: the high-speed train (a), the motor bogie (b) and the monitoring point (c).

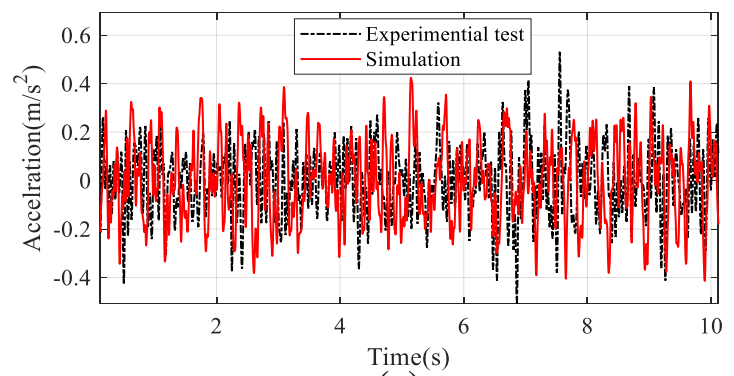

(a)

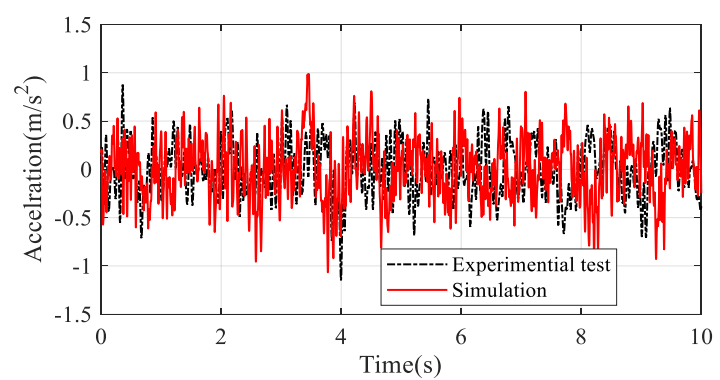

(c)

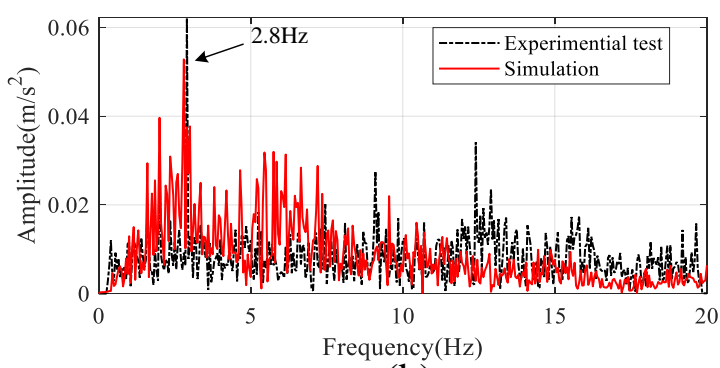

(b)

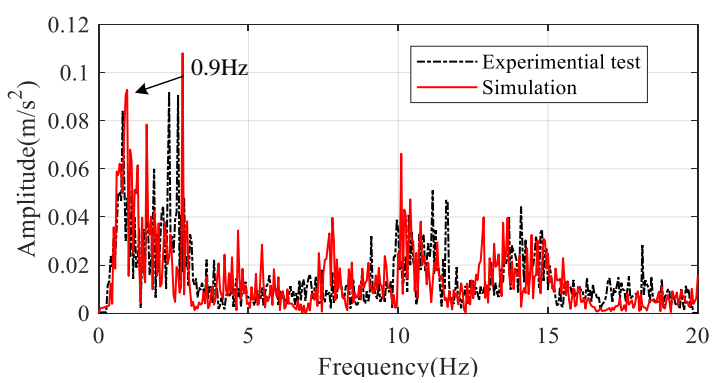

(d)

Figure 5. Validation of vehicle-track model by comparison with experimental test: lateral acceleration of carbody in time domain (a) and frequency domain (b); vertical acceleration of carbody in the time domain (a) and frequency domain (b). 


\section{Pantograph-catenary formulations}

\subsection{Catenary model}

As shown in Figure 6, the contact wire is responsible for providing electrical energy through a pantograph to the high-speed train. The messenger wire and droppers support the contact wire to keep its level or having a certain amount of pre-sag. In order to properly describe the nonlinearities of the catenary (including the unsmooth nonlinearity of droppers, and the geometrical nonlinearity of the contact/messenger wire), the flexible cable element is adopted to model the contact and messenger wires, and the truss element is used to model the dropper and steady arm. The claws on droppers and steady arms are considered as lumped masses. Following describes the cable and truss elements used in the catenary model.

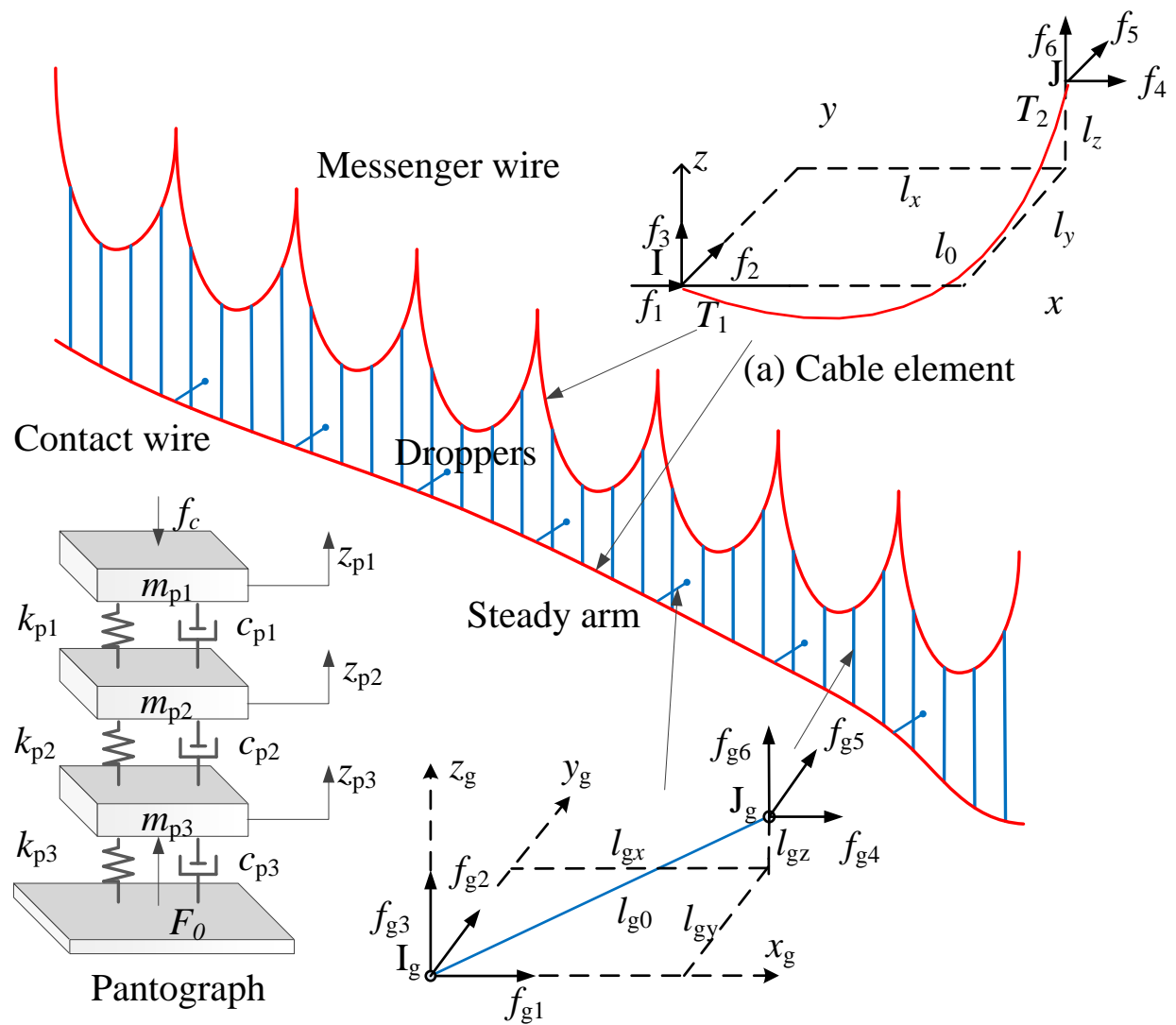

(b) Truss element

Figure 6. Finite element model of catenary with a lumped mass model of pantograph 


\subsubsection{Nonlinear cable element}

Considering a cable element with two nodes as shown in Figure 6, the relative distances between the two nodes can be expressed by the nodal forces as [61]

$$
\begin{gathered}
l_{\mathrm{x}}=-\left(f_{1} l_{0}\right) /\left(E_{\mathrm{c}} A_{\mathrm{c}}\right)-f_{1}\left\{\ln \left(\sqrt{f_{4}^{2}+f_{5}^{2}+f_{6}^{2}}+f_{6}\right)-\right. \\
\left.\ln \left(\sqrt{f_{1}^{2}+f_{2}^{2}+f_{3}^{2}}-f_{3}\right)\right\} / w_{\mathrm{c}} \\
l_{\mathrm{y}}=-f_{2} l_{0} /\left(E_{\mathrm{c}} A_{\mathrm{c}}\right)+f_{2}\left\{\operatorname { l n } \left[\sqrt{f_{1}^{2}+f_{2}^{2}+\left(w_{\mathrm{c}} l_{0}-f_{3}\right)^{2}}\right.\right. \\
\left.\left.\quad+w_{\mathrm{c}} l_{0}-f_{3}\right]-\ln \left(\sqrt{f_{1}^{2}+f_{2}^{2}+f_{3}^{2}}-f_{3}\right)\right\} / w_{\mathrm{c}} \\
l_{\mathrm{z}}=-\left(f_{3} l_{0}\right) /\left(E_{\mathrm{c}} A_{\mathrm{c}}\right)+\left(w_{\mathrm{c}} l_{0}^{2}\right) /\left(2 E_{\mathrm{c}} A_{\mathrm{c}}\right)+ \\
{\left[\sqrt{f_{4}^{2}+f_{5}^{2}+f_{6}^{2}}-\sqrt{f_{1}^{2}+f_{2}^{2}+f_{3}^{2}}\right] / w_{\mathrm{c}}}
\end{gathered}
$$

The force equilibrium of the cable element can be expressed by

$$
f_{1}+f_{4}=0 \quad f_{5}+f_{2}=0 \quad f_{6}+f_{3}=w l_{0}
$$

If $l_{\mathrm{x}}, l_{\mathrm{y}}$, and $l_{\mathrm{z}}$ are given, $f_{1} \sim f_{6}$ can be solved by the Newton-Raphson method according to Eq. (11). Substituting Eq. (12) into Eq. (11), partial differentiation of both sides of Eq. (11) yields the following incremental relationships between the relative nodal distances and nodal forces.

$$
\left\{\begin{array}{l}
\Delta l_{\mathrm{x}} \\
\Delta l_{\mathrm{y}} \\
\Delta l_{\mathrm{z}}
\end{array}\right\}=\left[\begin{array}{lll}
\frac{\partial l_{\mathrm{x}}}{\partial f_{1}} & \frac{\partial l_{\mathrm{x}}}{\partial f_{2}} & \frac{\partial l_{\mathrm{x}}}{\partial f_{3}} \\
\frac{\partial l_{\mathrm{y}}}{\partial f_{1}} & \frac{\partial l_{\mathrm{y}}}{\partial f_{2}} & \frac{\partial l_{\mathrm{y}}}{\partial f_{3}} \\
\frac{\partial l_{\mathrm{z}}}{\partial f_{1}} & \frac{\partial l_{\mathrm{z}}}{\partial f_{2}} & \frac{\partial l_{\mathrm{z}}}{\partial f_{3}}
\end{array}\right]\left\{\begin{array}{c}
\Delta f_{1} \\
\Delta f_{2} \\
\Delta f_{3}
\end{array}\right\}+\left[\begin{array}{c}
\frac{\partial l_{\mathrm{x}}}{\partial l_{\mathrm{g} 0}} \\
\frac{\partial l_{\mathrm{y}}}{\partial l_{\mathrm{g} 0}} \\
\frac{\partial l_{\mathrm{z}}}{\partial l_{\mathrm{g} 0}}
\end{array}\right] \Delta l_{\mathrm{g} 0}
$$

Taking the inverse of the flexibility matrix in Eq. (13) yields the incremental equation of the cable element.

$$
\Delta \mathbf{F}_{\mathrm{C}}=\mathbf{K}_{\mathrm{C}} \Delta \mathbf{U}_{\mathrm{C}}+\mathbf{K}_{\mathrm{CL}} \Delta l_{0}
$$

in which, $\Delta \mathbf{F}_{\mathrm{C}}$ is the incremental nodal force vector. $\mathbf{K}_{\mathrm{C}}$ is the stiffness matrix related to the nodal displacements. $\Delta \mathbf{U}_{\mathrm{C}}$ is the incremental displacement vector. $\mathbf{K}_{\mathrm{CL}}$ is the stiffness matrix related to the unstrained length of the cable. 
The tension is applied on the endpoint of the messenger/contact wire. Considering a cable element with constant tension $T_{0}$, an additional constraint condition is given as follows.

$$
T_{0}=\sqrt{f_{1}^{2}+f_{2}^{2}+f_{3}^{2}}
$$

\subsubsection{Truss element}

The equilibrium equation of truss element in Figure 6 is written as follows.

$$
\begin{aligned}
& f_{\mathrm{g} 1}=-E_{\mathrm{g}} A_{\mathrm{g}}\left(\frac{l_{\mathrm{gx}}}{l_{\mathrm{g} 0}}-\frac{l_{\mathrm{gx}}}{\sqrt{l_{\mathrm{gx}}^{2}+l_{\mathrm{gy}}^{2}+l_{\mathrm{gz}}^{2}}}\right) \\
& f_{\mathrm{g} 2}=-E_{\mathrm{g}} A_{\mathrm{g}}\left(\frac{l_{\mathrm{ty}}}{l_{t 0}}-\frac{l_{\mathrm{gy}}}{\sqrt{l_{\mathrm{gx}}^{2}+l_{\mathrm{gy}}^{2}+l_{\mathrm{gz}}^{2}}}\right) \\
& f_{\mathrm{g} 3}=-E_{\mathrm{g}} A_{\mathrm{g}}\left(\frac{l_{\mathrm{gz}}}{l_{\mathrm{g} 0}}-\frac{l_{\mathrm{gz}}}{\sqrt{l_{\mathrm{gx}}^{2}+l_{\mathrm{gy}}^{2}+l_{\mathrm{gz}}^{2}}}\right)
\end{aligned}
$$

Considering a nonlinear dropper, $E_{\mathrm{g}} A_{\mathrm{g}}$ equals to zero when the dropper works in compression. Similarly, the stiffness matrix of the truss element can be obtained through differentiating both sides of Eq. (16) as follows.

$$
\Delta \mathbf{F}_{\mathrm{G}}=\mathbf{K}_{\mathrm{G}} \Delta \mathbf{U}_{\mathrm{G}}+\mathbf{K}_{\mathrm{GL}} \Delta l_{\mathrm{g} 0}
$$

in which, $\Delta \mathbf{F}_{\mathrm{G}}$ is the incremental nodal force vector. $\mathbf{K}_{\mathrm{G}}$ is the stiffness matrix related to the nodal displacements. $\Delta \mathbf{U}_{\mathrm{G}}$ is the incremental displacement vector. $\mathbf{K}_{\mathrm{GL}}$ is the stiffness matrix related to the unstrained length of the truss.

It should be noted that the terms related to $\Delta l_{0}$ and $\Delta l_{\mathrm{g} 0}$ in Eqs. (11) and (16) are used to calculate the initial shape of the catenary. They vanish in the consequent dynamic calculation.

\subsubsection{Shape-finding of catenary}

The shape-finding of the catenary is performed by TCUD method proposed by Kim and 
Le [62], which takes the unstrained lengths $\Delta l_{0}$ and $\Delta l_{\mathrm{g} 0}$ as unknown parameters, and formulates the stiffness matrix with nodal forces and unstrained length for each element. In this way, more constraint conditions should be provided to eliminate the undesirable deformations of the catenary. Assembling Eqs. (11) and (16) by FEM, the global incremental equilibrium equation for the whole catenary can be obtained as follows.

$$
\Delta \mathbf{F}_{\mathrm{c}}=\mathbf{K}_{\mathrm{c}} \Delta \mathbf{U}_{\mathrm{c}}+\mathbf{K}_{\mathrm{c}}^{\mathrm{L}} \Delta \mathbf{L}_{\mathrm{c}}=\left[\begin{array}{ll}
\mathbf{K}_{\mathrm{c}} & \mathbf{K}_{\mathrm{c}}^{\mathrm{L}}
\end{array}\right]\left[\begin{array}{l}
\Delta \mathbf{U}_{\mathrm{c}} \\
\Delta \mathbf{L}_{\mathrm{c}}
\end{array}\right]
$$

where $\Delta \mathbf{F}_{\mathrm{c}}$ is the unbalanced force vector. $\mathbf{K}_{\mathrm{c}}$ and $\mathbf{K}_{\mathrm{c}}^{\mathrm{L}}$ are the global stiffness matrices related to the incremental nodal displacement vector $\Delta \mathbf{U}_{\mathrm{c}}$ and the incremental unstrained length vector $\Delta \mathbf{L}_{\mathrm{c}}$, respectively. Assume that the total number of degrees of freedom is $n$, and the number of elements is $m$. So, $\left[\begin{array}{ll}\mathbf{K}_{\mathrm{c}} & \mathbf{K}_{\mathrm{c}}^{\mathrm{L}}\end{array}\right]$ is a $n \times(m+n)$ matrix. Since the total number of unknowns $(m+n)$ in Eq. (18) exceeds the total number of equations $n$, Eq. (18) has infinite solutions. Hence, additional constraint conditions are provided to control the solution of Eq. (18), according to the design specification, which has been given in [61] with details.

\subsubsection{Equation of motion for catenary}

In combination with a consistent mass matrix $\mathbf{M}_{c}$ and a Rayleigh damping matrix $\mathbf{C}_{\mathrm{c}}$, the equation of motion for the catenary can be written by

$$
\mathbf{M}_{\mathrm{c}} \Delta \ddot{\mathbf{U}}_{\mathrm{c}}(t)+\mathbf{C}_{\mathrm{c}}(t) \Delta \dot{\mathbf{U}}_{\mathrm{c}}(t)+\mathbf{K}_{\mathrm{c}}(t) \Delta \mathbf{U}_{\mathrm{c}}(t)=\Delta \mathbf{F}_{\mathrm{c}}(x, t)
$$

in which, the $\Delta \mathbf{F}_{\mathrm{c}}(x, t)$ on the right side is the incremental external force vector. At each

time instant, the stiffness matrix $\mathbf{K}_{\mathrm{c}}(t)$ is updated by the response obtained in a previous time step. By this way, the geometrical nonlinearity of the messenger/contact wire and the non-smooth nonlinearity of each dropper are properly considered. 


\subsection{Pantograph model}

In this paper, the pantograph is modelled by a lumped mass representation as illustrated in Figure 6. The mass. stiffness and damping are identified through experimental tests [19] to ensure that the model has the same frequency response to a real pantograph. The equation of motion for the pantograph can be expressed by

$$
\mathbf{M}_{\mathrm{p}} \ddot{\mathbf{U}}_{\mathrm{p}}(t)+\mathbf{C}_{\mathrm{p}} \dot{\mathbf{U}}_{\mathrm{p}}(t)+\mathbf{K}_{\mathrm{p}} \mathbf{U}_{\mathrm{p}}(t)=\mathbf{F}_{\mathrm{p}}(t)
$$

in which, $\mathbf{M}_{\mathrm{p}}, \mathbf{C}_{\mathrm{p}}$ and $\mathbf{K}_{\mathrm{p}}$ are the matrices of the mass, damping and stiffness of the pantograph. $\ddot{\mathbf{U}}_{\mathrm{p}}(t), \dot{\mathbf{U}}_{\mathrm{p}}(t)$ and $\mathbf{U}_{\mathrm{p}}(t)$ are the vectors of acceleration, velocity and displacement, respectively. The contact force and uplift force are contained in the external force vector $\mathbf{F}_{\mathrm{p}}(t)$.

\subsection{Pantograph-catenary interaction}

In this paper, a three-dimensional contact geometry between the pantograph strip and the contact wire is proposed, which considers the variation of the contact position along the registration strip due to the vehicle-track excitation and the stagger value. The details of this methodology are given in Section 4. The contact force $F_{\mathrm{pc}}(t)$ used to couple the pantograph and the catenary is evaluated as follows.

$$
F_{\mathrm{pc}}(t)= \begin{cases}K_{\mathrm{c}} \delta Z_{\mathrm{PC}}(t) & \text { if } \delta Z_{\mathrm{PC}}(t)>0 \\ 0 & \text { if } \delta Z_{\mathrm{PC}}(t) \leq 0\end{cases}
$$

It should be noted that the friction at the interface of pantograph-catenary, which may aggravate the wear of the contact surface $[20,63]$ is not involved.

\subsection{Verification of pantograph-catenary model}

Using the Newmark integration method, Eqs. (19-21) can be solved to obtain the response of pantograph-catenary interaction. In each time step, the Newton-Raphson method is used to calculate the nodal force and stiffness matrix of cable element. In this way, the 
geometrical nonlinearity is fully addressed. The details of the numerical procedure can be found in $[30,61]$. The world benchmark of pantograph-catenary models describes the results of 10 professional simulation tools around the world and provides an authoritative verification standard for other software. In order to gain the confidence of the present model, the comparisons of the contact force and the pantograph head uplift against other 10 professional tools are performed. The resulting contact force and pantograph head uplift evaluated by a 3D catenary operating at $320 \mathrm{~km} / \mathrm{h}$ are shown in Figure 7 (a-b). It is seen that the present model has the same level of accuracy as the participators of the benchmark.

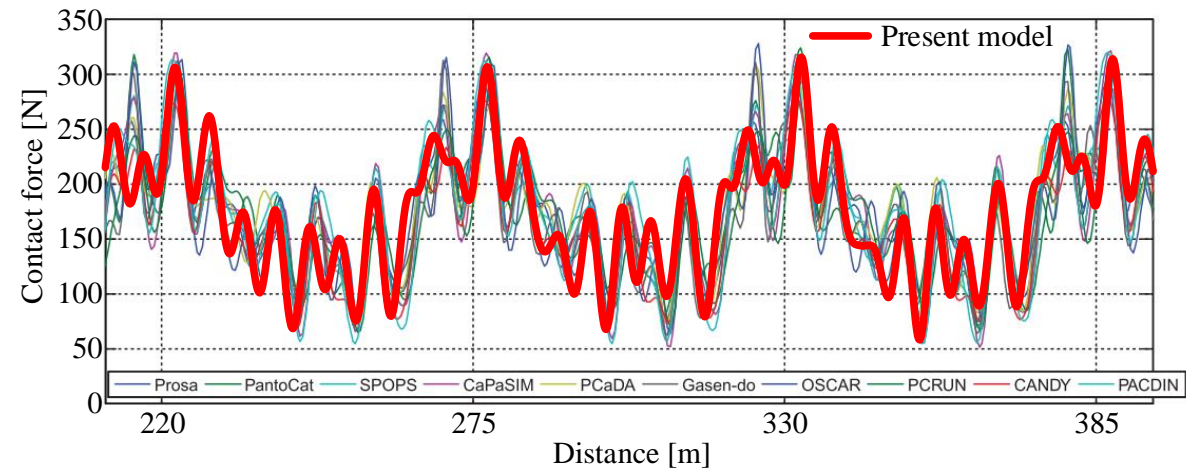

(a)

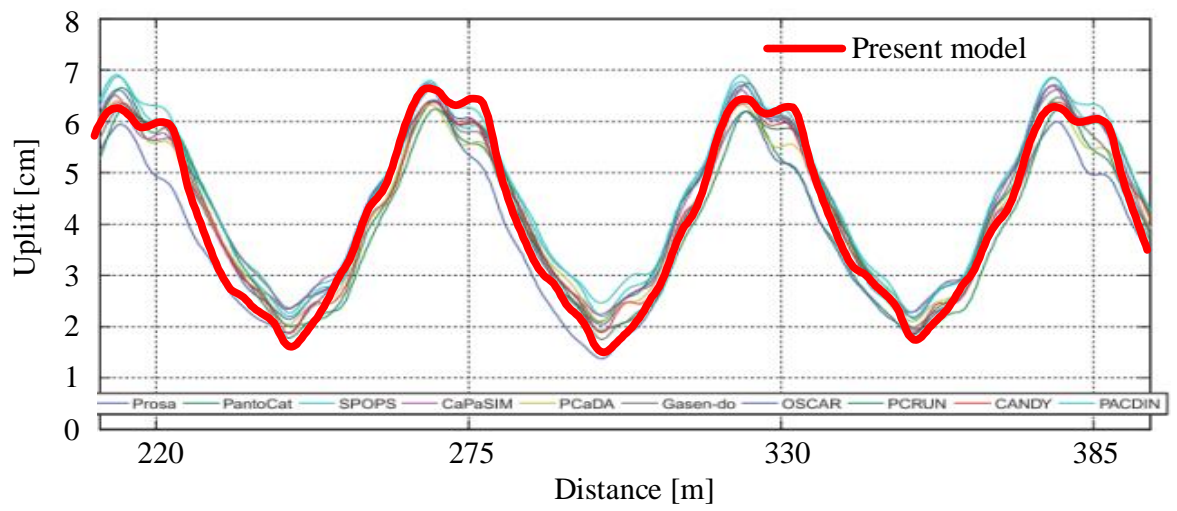

(b)

Figure 7. Verification of present model against Benchmark: Contact force (a); Pantograph head uplift (b) 


\section{Spatial coupling of two models}

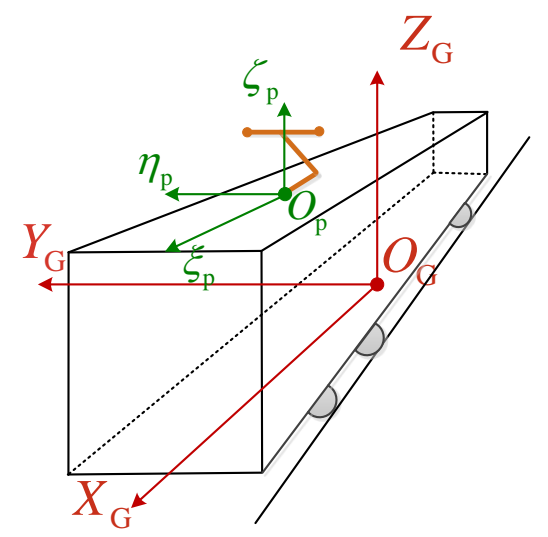

Figure 8. Representation of carbody coordinate and pantograph coordinate

In this section, the coupling method between the pantograph-catenary and the vehicletrack models is illustrated. As shown in Figure 8, a local reference frame of the $\operatorname{pantograph}\left(\xi_{\mathrm{p}}, \eta_{\mathrm{p}}, \zeta_{\mathrm{p}}\right)$ is defined to facilitate the illustration. If the carbody stays static, the local reference frame $\left(\xi_{\mathrm{p}}, \eta_{\mathrm{p}}, \zeta_{\mathrm{p}}\right)$ is parallel to the global reference frame $\left(X_{\mathrm{G}}, Y_{\mathrm{G}}\right.$, $Z_{\mathrm{G}}$ ). As the pantograph sits on the carbody roof, the movement of the carbody results in the rotation and offset of the local reference frame $\left(\xi_{\mathrm{p}}, \eta_{\mathrm{p}}, \zeta_{\mathrm{p}}\right)$. As shown in Figure 9, the reference frame $\left(\xi_{\mathrm{p}}^{\mathrm{k}}, \eta_{\mathrm{p}}^{\mathrm{k}}, \zeta_{\mathrm{p}}^{\mathrm{k}}\right)$ is caused by the traverse motion $Y_{\mathrm{cb}}$ and bounce $Z_{\mathrm{cb}}$ of the carbody. Due to the roll $\phi_{\mathrm{cb}}$, yaw $\psi_{\mathrm{cb}}$ and pitch $\beta_{\mathrm{cb}}$ of the carbody, the reference frame $\left(\xi_{\mathrm{p}}^{\mathrm{\kappa}}, \eta_{\mathrm{p}}^{\mathrm{\kappa}}, \zeta_{\mathrm{p}}^{\mathrm{k}}\right)$ is rotated to $\left(\xi_{\mathrm{p}}^{\lambda}, \eta_{\mathrm{p}}^{\lambda}, \zeta_{\mathrm{p}}^{\lambda}\right)$. For the contact model described in Eq. (21), the contact force calculation is dependent on the contact geometry of the pantograph strip and the contact wire. Points $A_{\mathrm{p}}$ and $B_{\mathrm{p}}$ represent the endpoints on the strip. The point positions $\mathbf{r}_{\mathrm{A}}^{\mathrm{G}}$ and $\mathbf{r}_{\mathrm{B}}^{\mathrm{G}}$ in the global reference frame $\left(X_{\mathrm{G}}, Y_{\mathrm{G}}, Z_{\mathrm{G}}\right)$ can be calculated by 

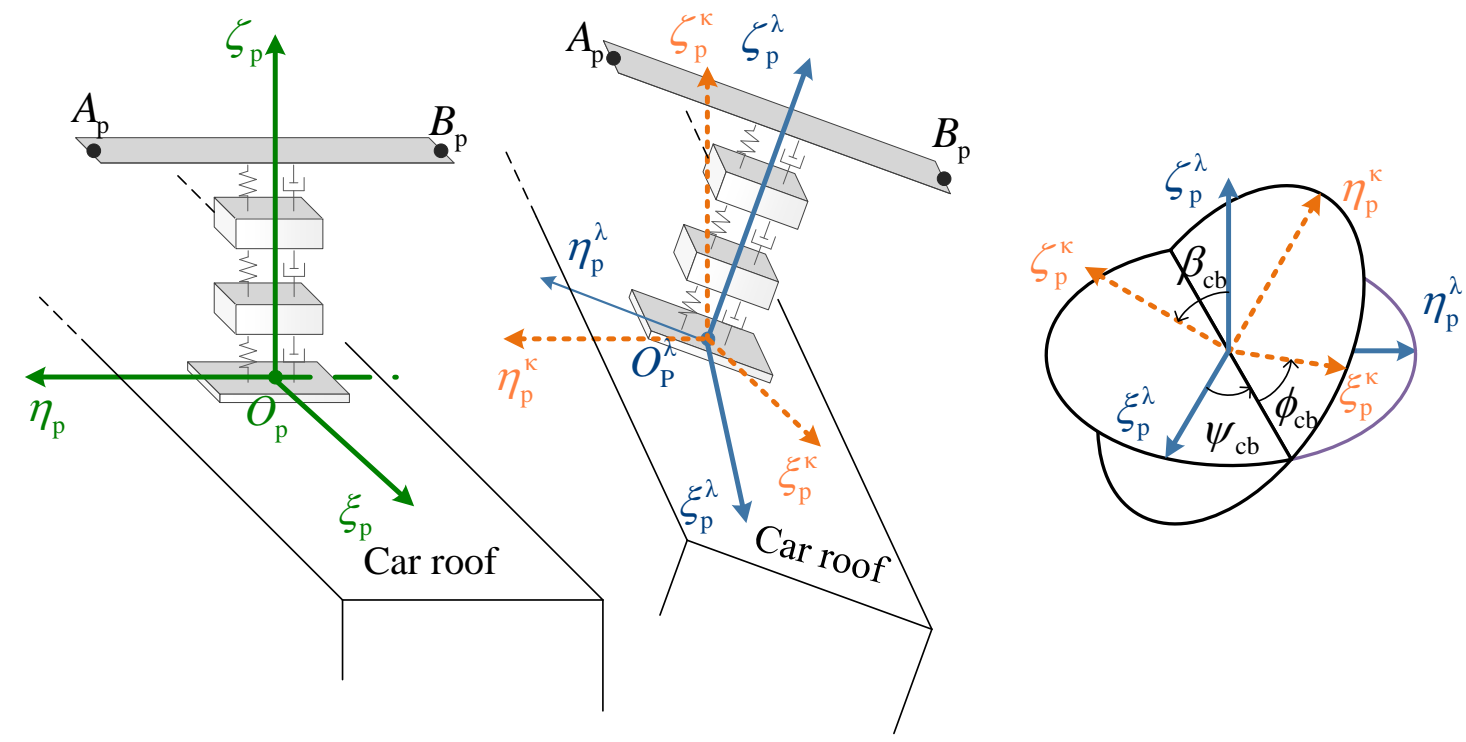

Figure 9. Rotation and offset of local reference frame due to the movement of carbody

$$
\begin{aligned}
& \mathbf{r}_{\mathrm{A}}^{\mathrm{G}}=\mathbf{r}_{O_{\mathrm{p}}}^{\mathrm{G}}-\mathbf{u}_{\mathrm{cb}}^{\mathrm{G} \rightarrow \kappa}+\mathbf{T}^{\lambda \rightarrow \kappa} \mathbf{r}_{\mathrm{A}}^{\lambda} \\
& \mathbf{r}_{\mathrm{B}}^{\mathrm{G}}=\mathbf{r}_{O_{\mathrm{p}}}^{\mathrm{G}}-\mathbf{u}_{\mathrm{cb}}^{\mathrm{G} \rightarrow \kappa}+\mathbf{T}^{\lambda \rightarrow \kappa} \mathbf{r}_{\mathrm{B}}^{\lambda}
\end{aligned}
$$

in which, $\mathbf{r}_{O_{\mathrm{p}}}^{\mathrm{G}}$ is the position of point $O_{\mathrm{P}}$ in the global reference frame $\left(X_{\mathrm{G}}, Y_{\mathrm{G}}, Z_{\mathrm{G}}\right)$.

The $\mathbf{u}_{\mathrm{cb}}^{\mathrm{G} \rightarrow \kappa}$ is the displacement vector of the carbody causing the offset of the local reference frame from $\left(\xi_{\mathrm{p}}, \eta_{\mathrm{p}}, \zeta_{\mathrm{p}}\right)$ to $\left(\xi_{\mathrm{p}}^{\mathrm{k}}, \eta_{\mathrm{p}}^{\mathrm{k}}, \zeta_{\mathrm{p}}^{\mathrm{k}}\right) . \mathbf{r}_{\mathrm{A}}^{\lambda}$ and $\mathbf{r}_{\mathrm{B}}^{\lambda}$ are the point positions in the reference frame $\left(\xi_{\mathrm{p}}^{\lambda}, \eta_{\mathrm{p}}^{\lambda}, \zeta_{\mathrm{p}}^{\lambda}\right) . \mathbf{T}^{\lambda \rightarrow \kappa}$ is the rotation matrix from $\left(\xi_{\mathrm{p}}^{\lambda}, \eta_{\mathrm{p}}^{\lambda}, \zeta_{\mathrm{p}}^{\lambda}\right)$ to ( $\left.\xi_{\mathrm{p}}^{\mathrm{k}}, \eta_{\mathrm{p}}^{\mathrm{\kappa}}, \zeta_{\mathrm{p}}^{\mathrm{k}}\right)$, which is determined by $\phi_{\mathrm{cb}}, \psi_{\mathrm{cb}}$ and $\beta_{\mathrm{cb}}$. 


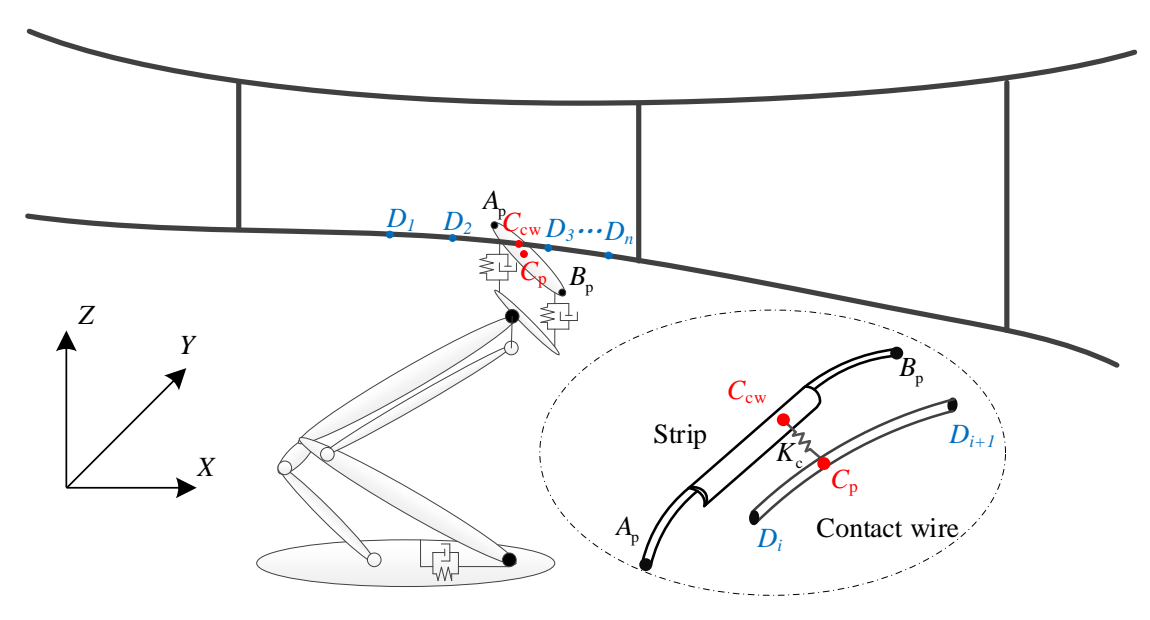

Figure 10. Representation of contact geometry between pantograph and catenary

Figure 10 shows the representation of the contact geometry between the pantograph and the contact wire. $D_{i}(i=1,2 \cdots n)$ are the finite element nodes on the contact wire. The potential contact point on the contact wire is contained in the segment from $D_{1}$ to $D_{n}$. $C_{\mathrm{p}}$ is the contact point on the pantograph strip, while $C_{\mathrm{cw}}$ is the contact point on the contact wire. The following mathematical procedure finds the exact positions of the two contact points.

If the contact occurs on the segment $D_{i} D_{i+1}$, the position of the contact point $\mathbf{r}_{C_{\mathrm{cw}}}^{\mathrm{G}}$ can be expressed by the positions of two nodes $\mathbf{r}_{D_{i}}^{\mathrm{G}}$ and $\mathbf{r}_{D_{i+1}}^{\mathrm{G}}$ as follows, according to the shape function of the cable element.

$$
\mathbf{r}_{C_{\mathrm{cw}}}^{\mathrm{G}}=\mathbf{r}_{D_{i}}^{\mathrm{G}}+\xi\left(\mathbf{r}_{D_{i+1}}^{\mathrm{G}}-\mathbf{r}_{D_{i}}^{\mathrm{G}}\right)
$$

in which, $\xi$ is the parametric length coordinate of the finite element, which can be obtained by finding the point of intersection between the lines $D_{i} D_{i+1}$ and $A B$, when projected to the same plane. According to [64], both lines are projected to the $X Y$ plane 
for convenience. The following equation can be obtained by the interception between the two lines projected to the $X Y$ plane.

$$
\mathbf{r}_{D_{i}}^{x y}+\mathbf{u}_{D_{i} \rightarrow D_{i+1}}^{x y} d_{D_{i} C_{\mathrm{cw}}}^{x y}=\mathbf{r}_{A}^{x y}+\mathbf{u}_{A \rightarrow B}^{x y} d_{A C_{\mathrm{p}}}^{x y}
$$

in which, $\mathbf{r}_{D_{i}}^{x y}$ and $\mathbf{r}_{A}^{x y}$ are the positons of $D_{i}$ and $A$ in the $X Y$ plane. $\mathbf{u}_{D_{i} \rightarrow D_{i+1}}^{x y}$ and $\mathbf{u}_{A \rightarrow B}^{x y}$ are the versors of generic vectors from $D_{i}$ to $D_{i+1}$, and from $A$ to $B$, respectively in the XY plane. $d_{D_{i} C_{\mathrm{cw}}}^{x y}$ and $d_{A C_{\mathrm{p}}}^{x y}$ are the distances between points $D_{i}$ and $C_{\mathrm{cw}}$, and points $A$ and $C_{\mathrm{p}}$, respectively, which can be obtained by solving Eq. (24). The parametric length coordinate $\xi$ is calculated by

$$
\xi=\frac{d_{D_{i} C_{\mathrm{cw}}}^{x y}}{\left\|\mathbf{r}_{D_{i+1}}^{x y}-\mathbf{r}_{D_{i}}^{x y}\right\|}
$$

If $\xi \in[0,1]$, the contact takes place in the contact wire segment $D_{i} D_{i+1}$. Otherwise, the next element should be checked.

As for the pantograph strip, the distance $d_{A C_{\mathrm{p}}}^{\mathrm{G}}$ between the points $A$ and $C_{\mathrm{p}}$ in the global reference frame can be calculated by

$$
d_{A C_{\mathrm{p}}}^{\mathrm{G}}=\mathbf{u}_{A \rightarrow B}^{\mathrm{G}}\left(\mathbf{r}_{C_{\mathrm{cw}}}^{\mathrm{G}}-\mathbf{r}_{A}^{\mathrm{G}}\right)
$$

in which, $\mathbf{u}_{A \rightarrow B}^{\mathrm{G}}$ is the versor of a generic vector from $A$ to $B$. So the position of the point $C_{\mathrm{p}}$ can be obtained by

$$
\mathbf{r}_{C_{\mathrm{p}}}^{\mathrm{G}}=\mathbf{r}_{A}^{\mathrm{G}}+d_{A C_{\mathrm{p}}}^{\mathrm{G}} \mathbf{u}_{A \rightarrow B}^{\mathrm{G}}
$$

Following the above procedure, the positions of the two contact points $C_{\mathrm{cw}}$ and $C_{\mathrm{p}}$ on the contact wire and the strip can be obtained. Then the penetration $\delta Z_{\mathrm{PC}}(t)$ of the contact surface between the pantograph and the catenary is evaluated, from which the contact force of pantograph-catenary is calculated by Eq. (21). In this way, the vehicle vibration is properly accounted for in the interaction of pantograph-catenary. The whole procedure is illustrated in Figure 11. It is seen that the simulation is a one-way procedure. The 
vehicle-track model is run firstly to obtain the carbody motions in each time step. In the pantograph-catenary simulation, the pantograph height and 6 DOF carbody motion are used to formulate the translation vector and rotation matrix. Then the endpoint positions of pantograph strip are determined by a spatial coordinate transformation. Thus, the contact point can be identified according to the spatial positions of the pantograph strip and contact wire. Finally, the contact force is calculated and exerted on the pantographcatenary system to calculate the response in this time step.

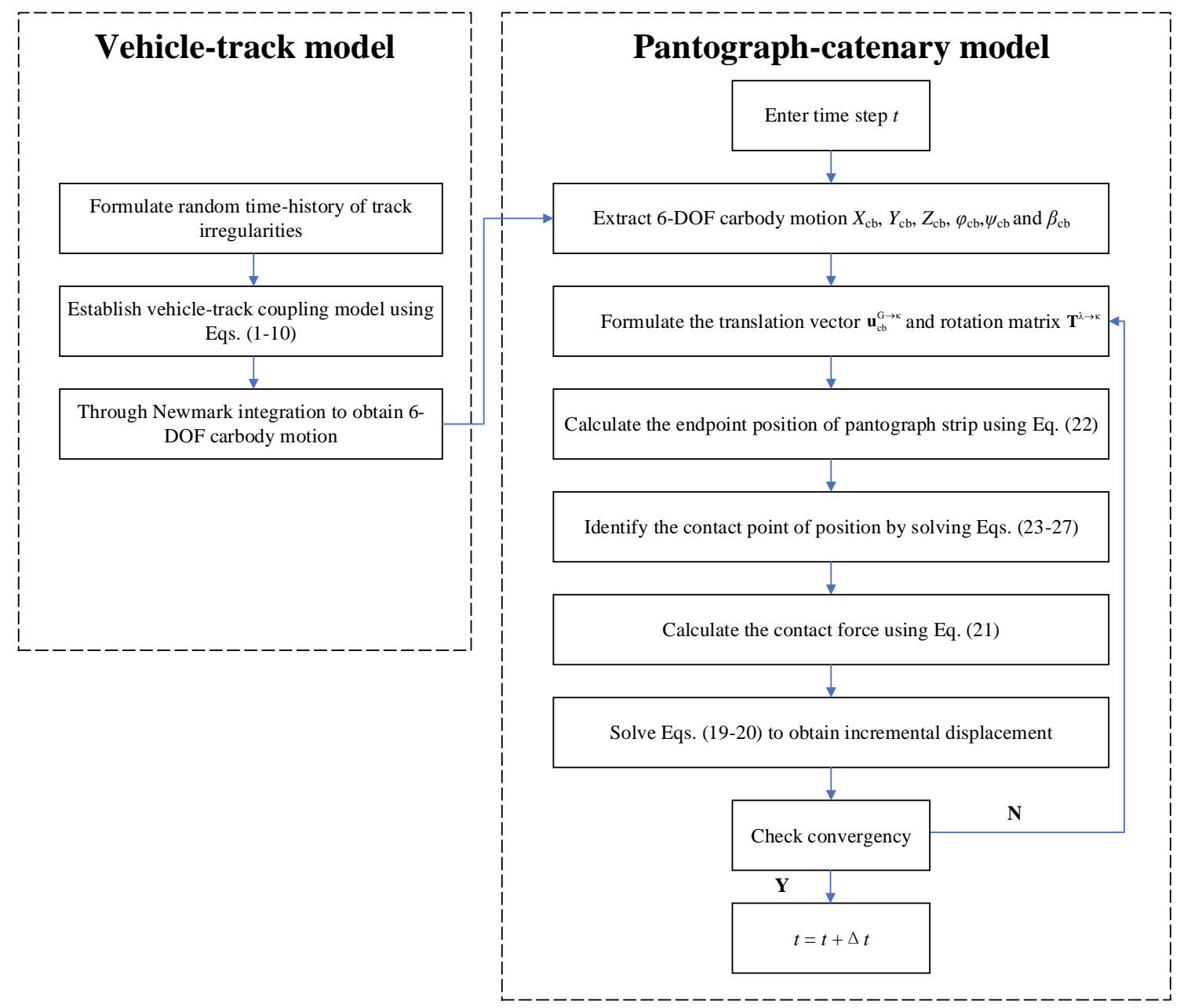

Figure 11. Simulation procedure for vehicle-track and pantograph-catenary interaction

\section{Analysis with random track irregularities}

As is well known, the track irregularity is the main source of vehicle vibration. In this section, the dynamic performance of pantograph-catenary is evaluated with different 
levels of rail qualities. Without loss of generality, the reference model of pantographcatenary in the benchmark is adopted in the following analyses. A 20-span of catenary is established, and the central 10 spans are selected as an analysis object. The train speed is defined as $320 \mathrm{~km} / \mathrm{h}$ according to the benchmark [22]. As for the vehicle-track, a typical EMU model present in [65] is adopted. It should be noted that normally the high-speed train is not allowed to operate with awful track condition to ensure the comfort, stability and safety of the operation. However, the purpose of this section is not to reproduce the realistic phenomenon, but to make sense of the interaction performance of pantographcatenary with different levels of track quality.

The geometry of rail is affected by many realistic factors, which exhibit significant stochastics and represent the irregularities of the rail surface. In this paper, the effect of the vehicle-track excitation on the pantograph-catenary interaction is studied with different levels of rail irregularities. The PSD function is a normal representative of the random rail irregularities. As shown in Table 1, the coefficients of the PSD functions of rail irregularities are given with different levels of rail health conditions, which are summarised from the realistic measured data [66]. The rail quality improves with the increase of the level from 1 to 6 . The time-history of track irregularities is generated by the inverse Fourier transformation [57]. The frequency spectrum $\mathrm{X}(\mathrm{k})$ is obtained by discrete sampling from the standard spectral density function. The real and imaginary parts of $X(\mathrm{k})$ have even and odd symmetries with respect to $N_{\mathrm{r}} / 2$. Hence, the frequency spectrum $X(\mathrm{k})\left(k=0,1, \ldots, N_{r} / 2\right)$ is determined as follows:

$$
X(k)=|X(k)|\left(\cos \phi_{k}+i \sin \phi_{k}\right) \quad\left(k=0,1, \ldots, \quad N_{r} / 2\right)
$$

where $\phi_{k}$ is the phase angle and obeys the uniform distribution of $0-2 \pi$, and $N_{\mathrm{r}}$ denotes the sampling points. Then, the track irregularities are calculated using inverse Fourier Transform as 


$$
x(n)=\frac{1}{N_{r}} \sum_{k=0}^{N_{r}-1} X(k) \exp \left[\frac{i 2 \pi k n}{N_{r}}\right] \quad\left(n=0,1, \ldots, N_{r}-1\right)
$$

The time histories of track irregularity for each level are presented in Figure 12. Taking level 6 as an example, Figure 13 shows the comparison of the spectrum between the generated signal and the original signal. The validation of the present method can be verified by the high consistency of the two spectrums.

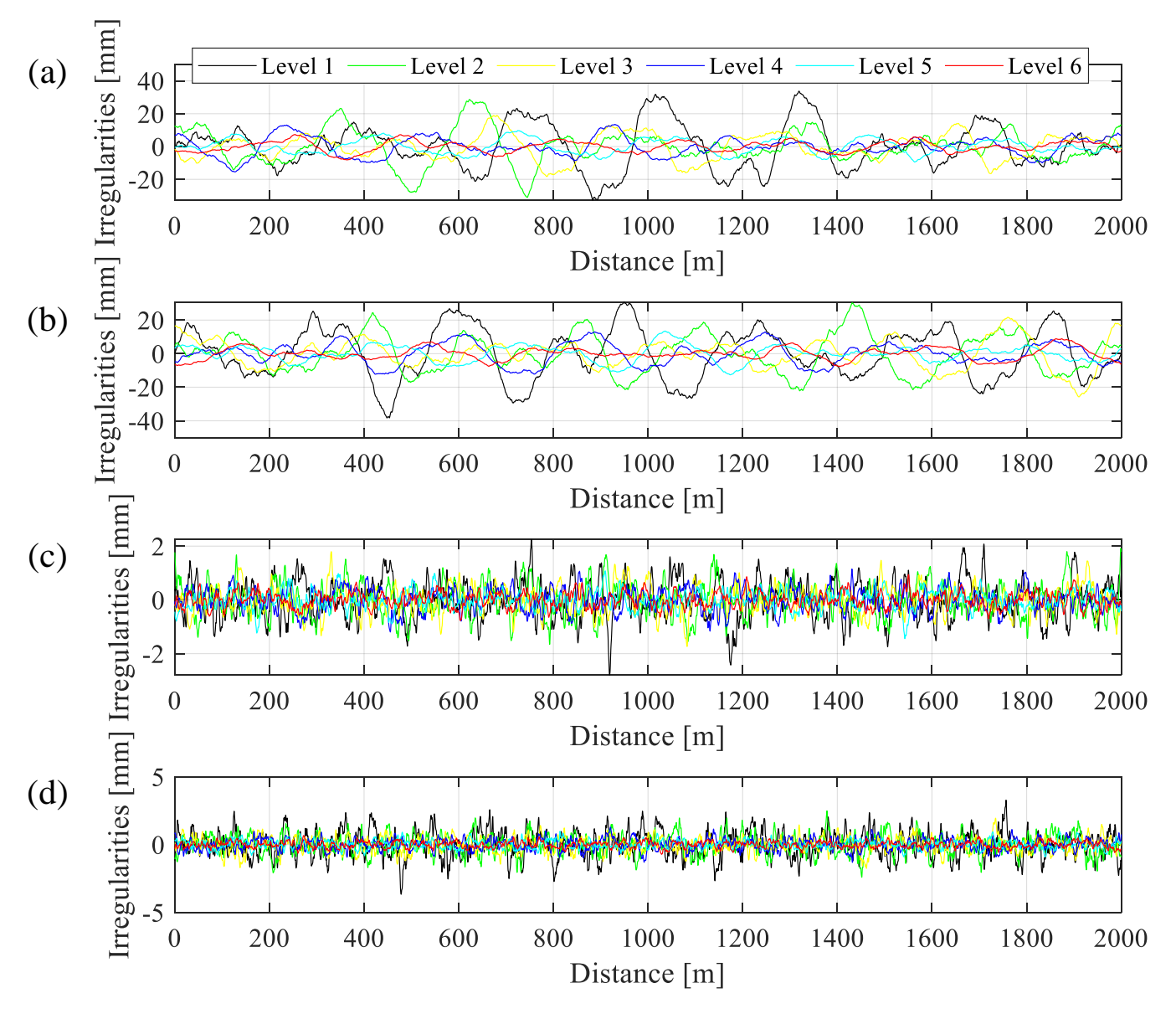

Figure 12. Time histories of track irregularities: Profile (a); Alignment (b); Crosslevel (c); Gage (d) 


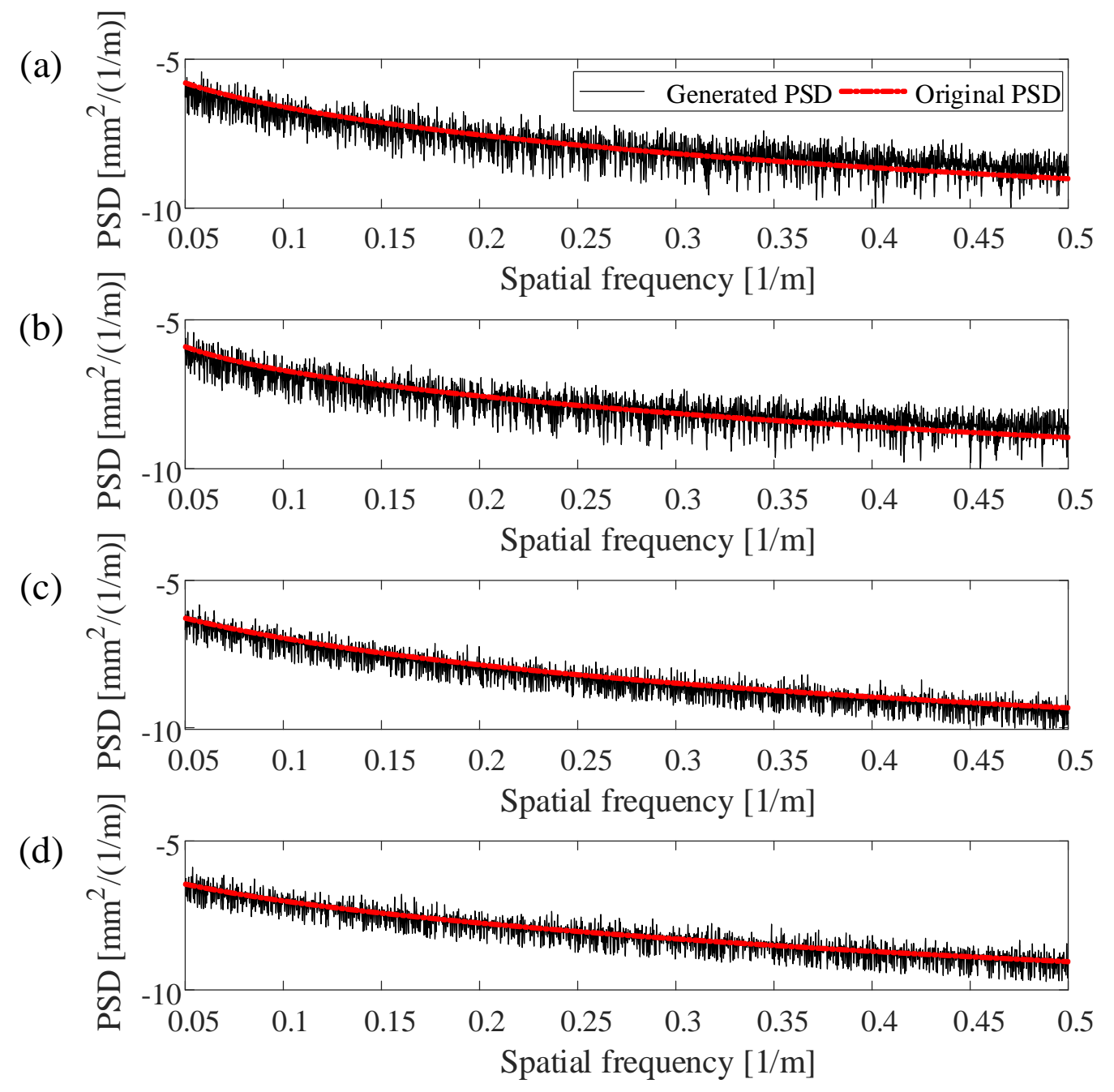

Figure 13. Comparison of the spectrum between the generated signal and the original signal: Profile (a); Alignment (b); Crosslevel (c); Gage (d)

Table 1. Coefficients of rail irregularities with different rail levels

\begin{tabular}{cccccccc}
\hline Type & Coefficient & \multicolumn{7}{c}{ Rail quality level } \\
& & 1 & 2 & 3 & 4 & 5 & 6 \\
\hline Profile & $A_{\mathrm{v}} /\left(10^{-7} \mathrm{~m}\right)$ & 16.72 & 9.53 & 5.29 & 2.96 & 1.67 & 0.95 \\
$S_{\mathrm{v}}(\phi)=\frac{A_{\mathrm{v}} \phi_{\mathrm{v} 2}^{2}\left(\phi^{2}+\phi_{\mathrm{v} 1}^{2}\right)}{\phi^{4}\left(\phi^{2}+\phi_{\mathrm{v} 2}^{2}\right)}$ & $\phi_{\mathrm{v} 1} /\left(10^{-2} \mathrm{~m}\right)$ & 2.33 & 2.33 & 2.33 & 2.33 & 2.33 & 2.33 \\
& $\phi_{\mathrm{v} 2} /\left(10^{-1} \mathrm{~m}\right)$ & 1.31 & 1.31 & 1.31 & 1.31 & 1.31 & 1.31 \\
\hline Alignment & $A_{\mathrm{a}} /\left(10^{-7} \mathrm{~m}\right)$ & 10.58 & 10.58 & 10.58 & 10.58 & 10.58 & 10.58
\end{tabular}




\begin{tabular}{|c|c|c|c|c|c|c|c|}
\hline \multirow{2}{*}{$S_{\mathrm{a}}(\phi)=\frac{A_{\mathrm{a}} \phi_{\mathrm{a} 2}^{2}\left(\phi^{2}+\phi_{\mathrm{a} 1}^{2}\right)}{\phi^{4}\left(\phi^{2}+\phi_{\mathrm{a} 2}^{2}\right)}$} & $\phi_{\mathrm{a} 1} /\left(10^{-2} \mathrm{~m}\right)$ & 3.28 & 3.28 & 3.28 & 3.28 & 3.28 & 3.28 \\
\hline & $\phi_{\mathrm{a} 2} /\left(10^{-1} \mathrm{~m}\right)$ & 1.84 & 1.84 & 1.84 & 1.84 & 1.84 & 1.84 \\
\hline \multirow{3}{*}{$S_{\mathrm{c}}(\phi)=\frac{A_{\mathrm{c}} \phi_{\mathrm{c} 2}^{2}}{\left(\phi^{2}+\phi_{\mathrm{c} 1}^{2}\right)\left(\phi^{2}+\phi_{\mathrm{c} 2}^{2}\right)}$} & $A_{\mathrm{c}} /\left(10^{-7} \mathrm{~m}\right)$ & 4.87 & 3.39 & 2.33 & 1.57 & 1.06 & 0.72 \\
\hline & $\phi_{\mathrm{cl}} /\left(10^{-2} \mathrm{~m}\right)$ & 2.33 & 2.33 & 2.33 & 2.33 & 2.33 & 2.33 \\
\hline & $\phi_{\mathrm{c} 2} /\left(10^{-1} \mathrm{~m}\right)$ & 1.31 & 1.31 & 1.31 & 1.31 & 1.31 & 1.31 \\
\hline \multirow{3}{*}{$S_{\mathrm{g}}(\phi)=\frac{A_{\mathrm{g}} \phi_{\mathrm{g} 2}^{2}}{\left(\phi^{2}+\phi_{\mathrm{g} 1}^{2}\right)\left(\phi^{2}+\phi_{\mathrm{g} 2}^{2}\right)}$} & $A_{\mathrm{g}} /\left(10^{-7} \mathrm{~m}\right)$ & 10.58 & 5.93 & 3.39 & 1.88 & 1.06 & 0.59 \\
\hline & $\phi_{\mathrm{g} 1} /\left(10^{-2} \mathrm{~m}\right)$ & 2.92 & 2.92 & 2.92 & 2.92 & 2.92 & 2.92 \\
\hline & $\phi_{\mathrm{g} 2} /\left(10^{-1} \mathrm{~m}\right)$ & 2.33 & 2.33 & 2.33 & 2.33 & 2.33 & 2.33 \\
\hline
\end{tabular}

\subsection{Statistical analysis}

In order to describe the stochastic characteristics of the rail irregularities, 500 different simulations of each level of irregularities are carried out based on the idea of Monte Carlo. These 500 simulations provide a wide range of variability in the track profile, assuming the normal distribution according to the limit central theorem.

The contact force of pantograph-catenary is the direct reflection of the current collection quality. In this section, the statistical values of the contact force are analysed to make sense of the effect of rail irregularities on the quality of current collection. To facilitate the analysis, the boxplots of all indices are adopted here. The boxplot is a standardized way to display the distribution of data based on a summary of five numbers, which are the minimal value $Q_{\min }$, the first quartile $Q_{1}$, the median $Q_{2}$, the third quartile $Q_{3}$, and the maximal value $Q_{\max }$. Usually the maximal and minimal can be calculated by the following two equations respectively.

$$
\begin{aligned}
& Q_{\text {max }}=Q_{3}+1.5 \times I Q R \\
& Q_{\text {min }}=Q_{1}-1.5 \times I Q R
\end{aligned}
$$


in which, IQR is the range from the $25^{\text {th }}$ to $75^{\text {th }}$ percentile. The outlier data which are out of the range $Q_{\min } \sim Q_{\max }$ are denoted by red 'plus'. Figure 14 shows the boxplots of statistical values of the contact force with different levels of rail irregularities, including the standard deviation, the mean value, the maximum value, the actual minimal value, the statistical maximum value and the statistical minimal value. Figure 15 shows an example of the contact force with each level of track quality. The effect of the rail irregularities on the contact fore of pantograph-catenary is quite complicated. The fluctuation range of the standard deviation becomes larger with the degradation of the rail quality. In the case of the worst rail quality, the maximum standard deviation reaches $60.77 \mathrm{~N}$, which represents a large fluctuation of the contact force. However, the minimal standard deviation is only $50.66 \mathrm{~N}$, which is even better than the case without rail irregularities. The rail irregularity also brings a slight variance to the mean contact force. However, when looking at the maximum and minimal values, the negative effect of rail irregularity can be significantly observed. The actual maximum value undergoes a significant increase with the degradation of rail irregularities, while the minimal value experiences a continuous decrease.

According to the standard [67], the statistical maximum and minimal values of the contact force are the important indices to evaluate the dynamic performance of the pantograph-catenary system. As shown in Figure 14(e), some statistical maximum values exceed the safety threshold $(350 \mathrm{~N})$ in the cases of bad rail quality. Similarly, some statistical minimal values are lower than the safety threshold $(0 \mathrm{~N})$ except the case of the best rail quality (level 6). Therefore, the vehicle vibration significantly aggravates the safe operation of the pantograph-catenary operation. 


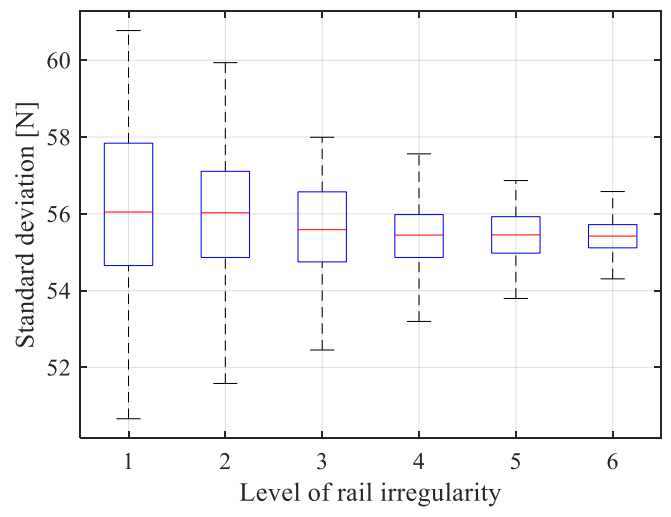

(a)

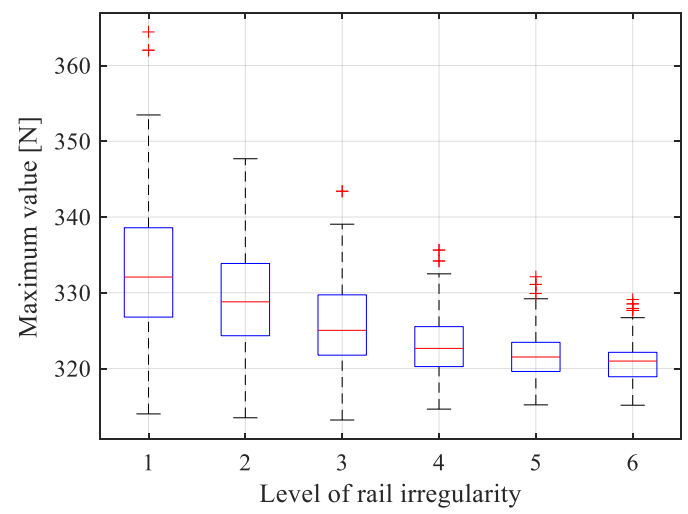

(c)

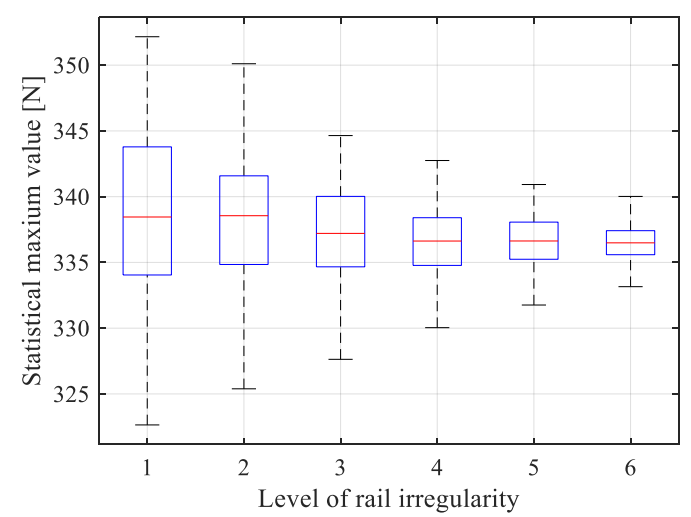

(e)

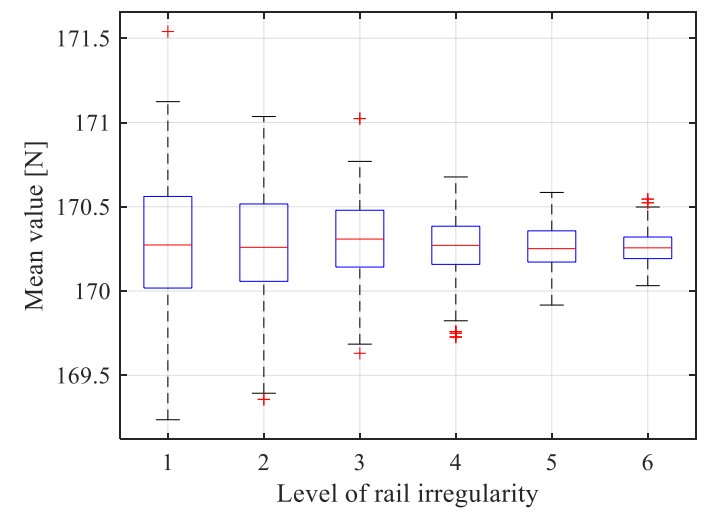

(b)

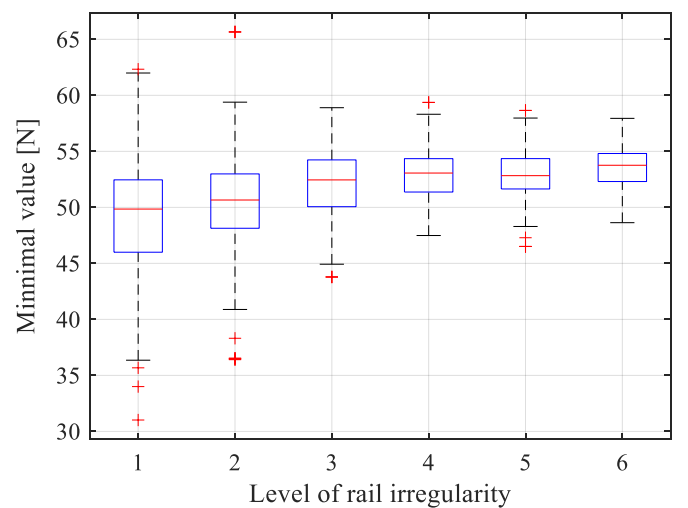

(d)

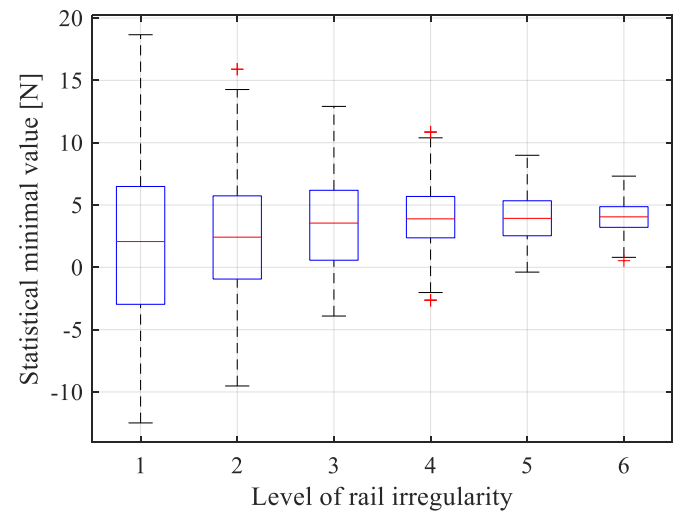

(f)

Figure 14. Boxplots of statistical values of contact force: standard deviation (a); mean value (b); maximum value (c); minimal value (d); statistical minimal value (e); statistical maximum value (f) 


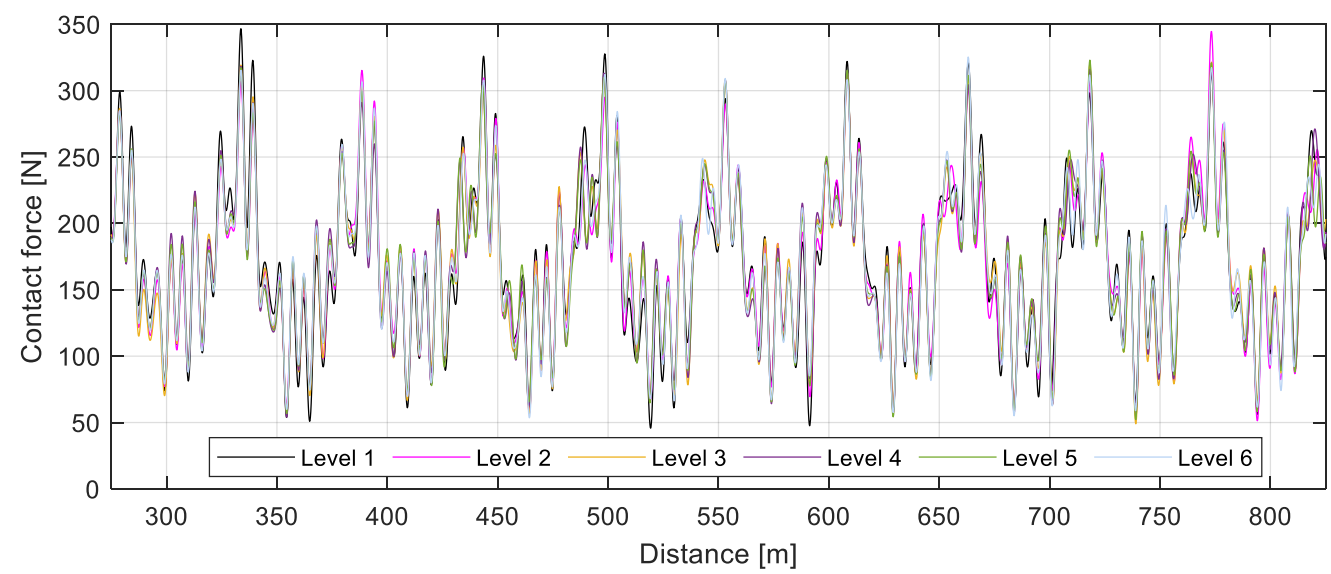

Figure 15. Examples of contact force with different levels of track quality

\subsection{Probabilistic analysis}

The probability density function can be used to specify the probability of the random variable falling within a specified range of values. As the random vibration response of the locomotive exhibits strong normality with the excitation of track irregularities [68], the statistical values of pantograph-catenary interaction are assumed to obey the normal distribution. The PDFs of the statistical maximum and minimal values are present in Figure 16. For the statistical maximum value, the probability of exceeding the safety threshold increases up to $2.75 \%$ with the worst rail quality (level 1). When the rail quality is above level 3, all the statistical maximum values fall in the safety region. For the statistical minimal value, the probability of exceeding the safety threshold decreases from $44 \%$ to 0 , with the improvement of the rail quality from level 1 to 6 . Figure 17 (a-f) show the joint PDFs associated with the joint information of statistical maximum and minimal values, with six levels of rail qualities, respectively. It can be seen that the risk region highlighted in red bars significantly increases with the degradation of rail quality. Both of the statistical minimal and maximum values fall in the safety region only in the case of the best rail quality (level 6). 
Furthermore, the reliability is a quantitative index to describe the capability of the pantograph-catenary system to complete its required function, which can be calculated by

$$
P_{\mathrm{R}}\left(\rho<\rho_{\mathrm{m}}, \delta>\delta_{\mathrm{m}}\right)=\int_{-\infty}^{\rho_{\mathrm{m}}} \int_{\delta_{\mathrm{m}}}^{+\infty} p(\rho, \delta) \mathrm{d} \delta \mathrm{d} \rho
$$

In which, $\rho$ and $\delta$ represent the statistical maximum and minimal values of the contact force. $p(\rho, \delta)$ is the joint probability distribution associated with $\rho$ and $\delta . \rho_{\mathrm{m}}$ and $\delta_{\mathrm{m}}$ are the corresponding safety thresholds, which are defined as $350 \mathrm{~N}$ and $0 \mathrm{~N}$ according to the standard. Based on the calculation results presented in Figure 17, the reliability degrees with six levels of rail qualities are collected in Table 2. The statistical maximum value falls in the safe region when the rail quality upgrades to level 3 . The joint reliability of pantograph-catenary can be significantly reduced by the degradation of rail quality. If the minimal reliability is required to be 0.98 , the rail quality should be maintained at level 5 or above.

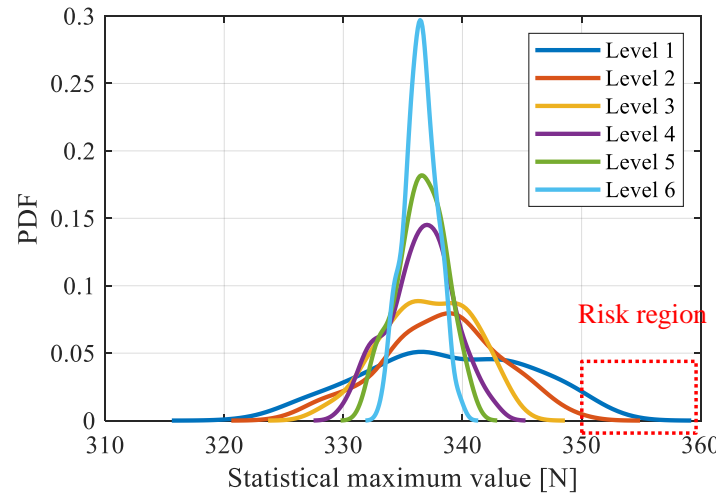

(a)

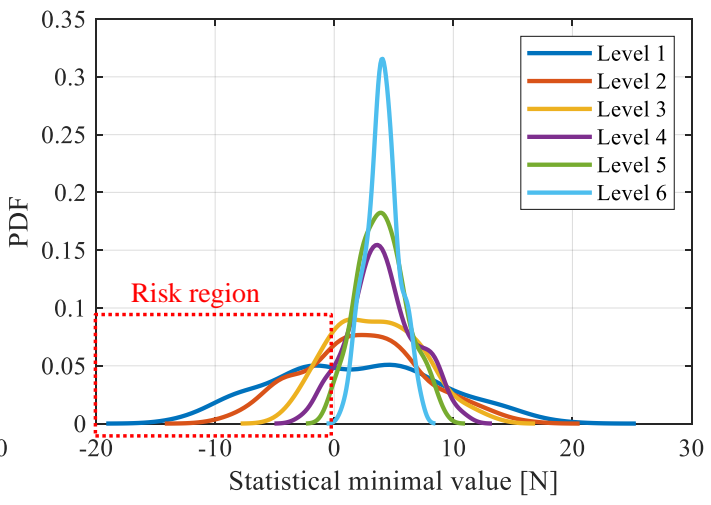

(b)

Figure 16. PDFs of statistical maximum value (a) and statistical minimal value (b) 


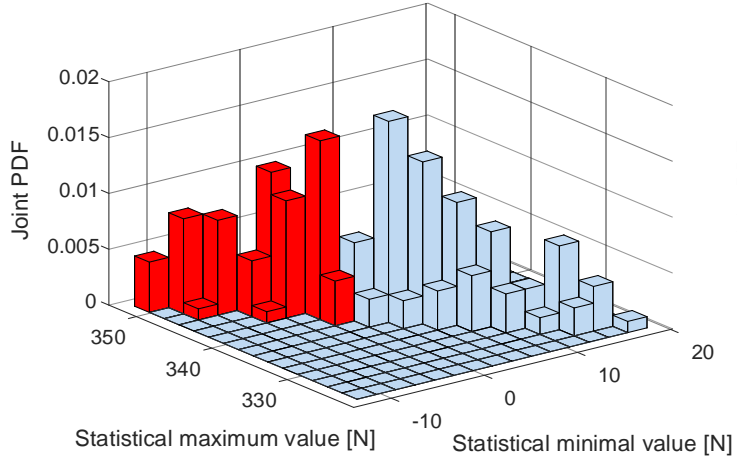

(a)

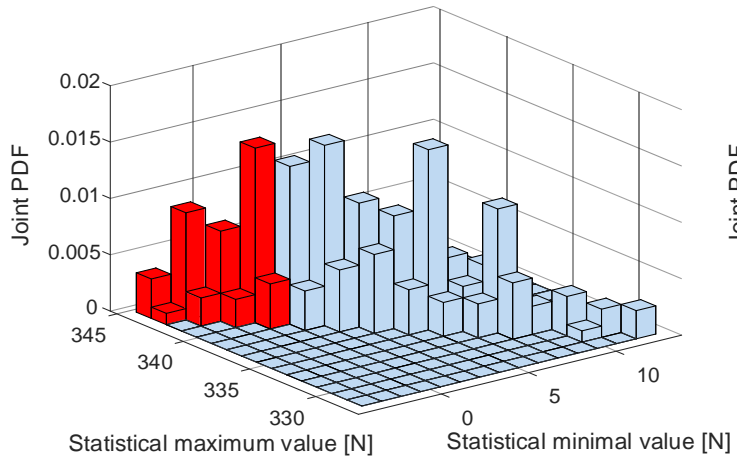

(c)

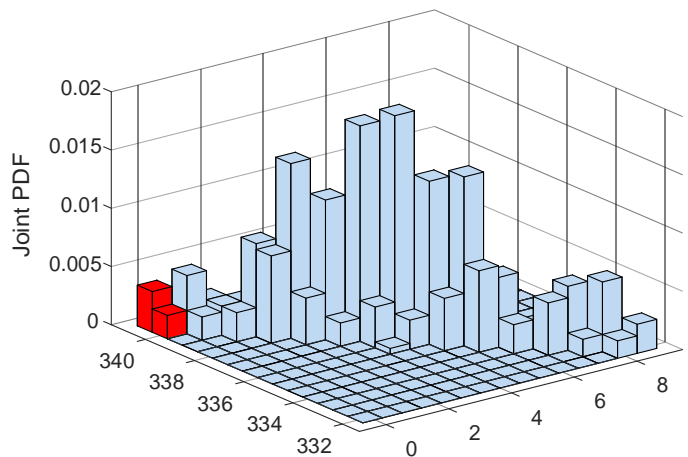

Statistical maximum value $[\mathrm{N}]$

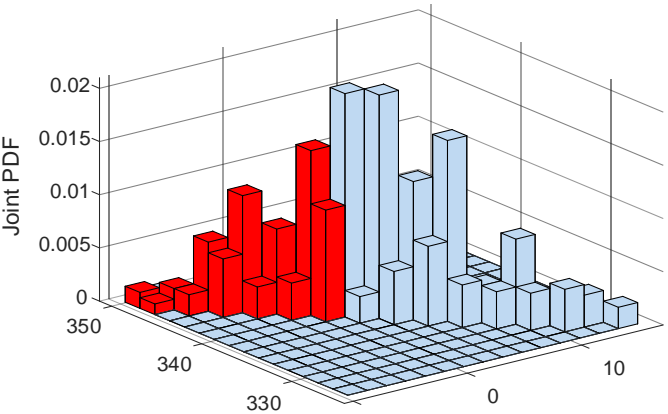

Statistical maximum value $[\mathrm{N}]^{-10}$ Statistical minimal value $[\mathrm{N}]$

(b)

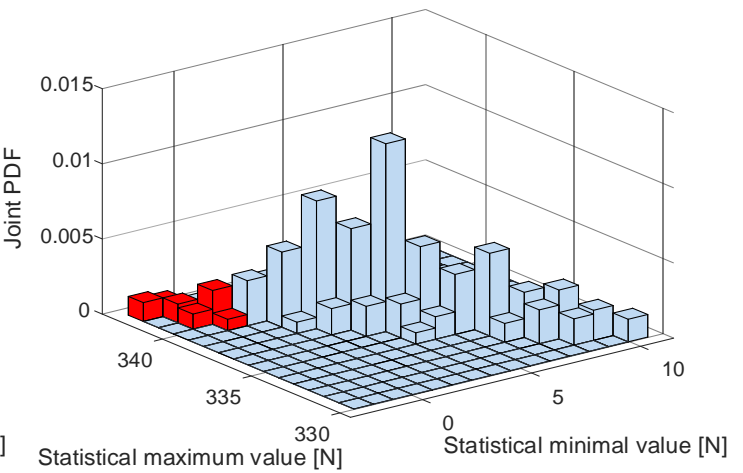

(d)

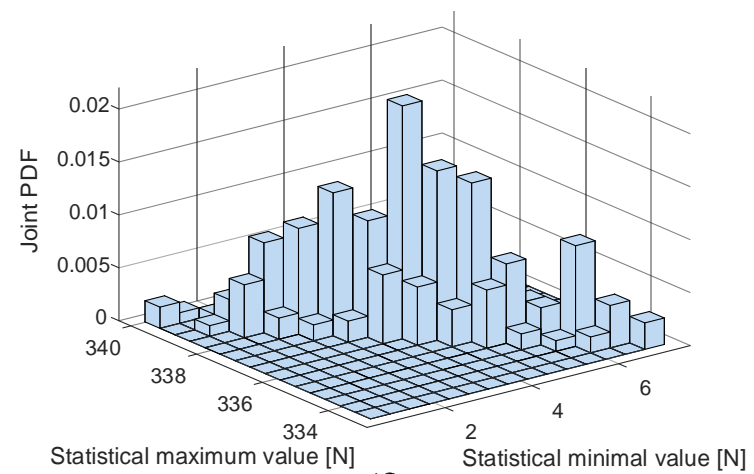

(f)

Figure 17. Joint PDFs of statistical maximum and minimal values with levels 1-6 (a-f) of rail irregularities

Table 2. Reliability of pantograph-catenary with different levels of rail quality

\begin{tabular}{ccccccc}
\hline & \multicolumn{7}{c}{ Level of rail irregularities } \\
& 1 & 2 & 3 & 4 & 5 & 6 \\
\hline S. Max & 0.973 & 0.995 & 1 & 1 & 1 & 1 \\
S. Min & 0.56 & 0.71 & 0.82 & 0.92 & 0.98 & 1 \\
Joint & 0.56 & 0.71 & 0.82 & 0.92 & 0.98 & 1 \\
\hline
\end{tabular}




\subsection{PSD analysis}

The Yule-Walker method is employed to estimate the spectral density of the contact force calculated by a total of 500 simulations. Figure 18 shows the PSDs of contact force with six levels of rail irregularities. In order to evaluate the contribution of the vehicle vibration to the variance of the contact force, the mean values are subtracted from the results before the PSD estimation. It is seen that the PSD peaks appear at several spatial frequencies relevant to the span length, the half-span length, and the intervals between droppers and steady arms. The degradation of the rail quality results in a general increase of the energy over the entire frequency range of interest, which can be clearly demonstrated by the enlarged region. The random rail irregularity can be seen as a broadband excitation to the pantograph-catenary system, whose contribution is in the whole frequency range, but not at specific frequencies.

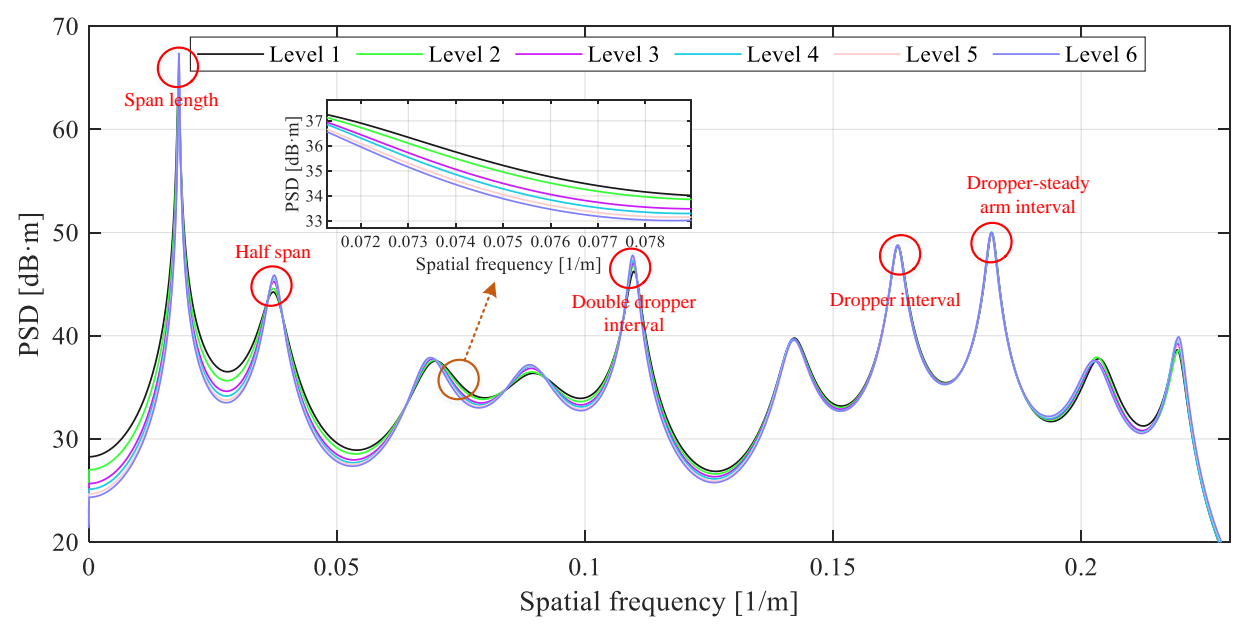

Figure 18. PSDs of contact force with six levels of rail irregularities

\subsection{Contact point}

Apart from the above analyses relevant to contact force, this section analyses the variances of the contact point position on the pantograph strip, which may be affected by the movement of the carbody. As illustrated in Figure 19, the distance $d_{\mathrm{p}}$ between the 
contact point $C_{\mathrm{p}}$ and the centre of the strip $G_{\mathrm{p}}$ is calculated to assess the risk of dewirement. Figure 20 presents the boxplot of $d_{\mathrm{p}}$ with six levels of rail quality. It should be noted that the stagger value of the present catenary is $0.2 \mathrm{~m}$. The motion of carbody brings more lateral variations to the pantograph base. The deviation of the contact point away from the strip centre undergoes a significant increase with the degradation of rail quality. The maximum deviation reaches $0.26 \mathrm{~m}$ with the worse rail quality, which still falls in the working range of this type of pantograph. However, the maximum deviation of the contact wire caused by the wind load should not exceed $0.4 \mathrm{~m}$ [67]. If the extreme condition is considered, the contact point may be outside the safety range. Thus, dewirement assessment is necessary to be performed with extreme conditions (strong wind and poor rail quality) in the future.

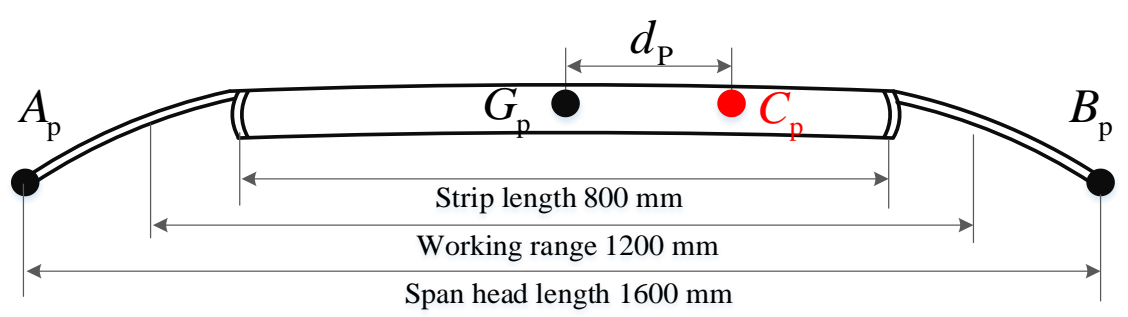

Figure 19. Schematic of pantograph strip

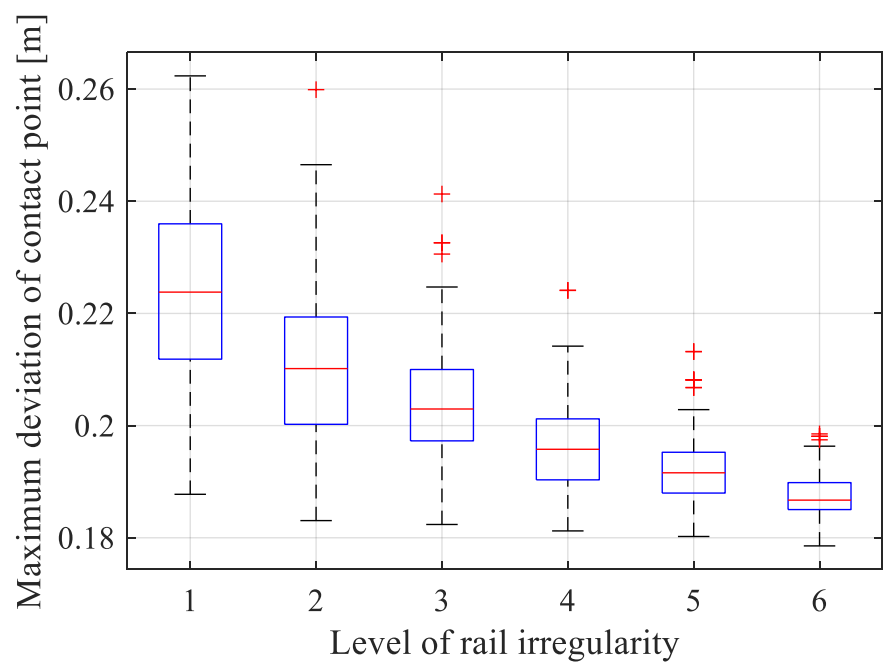


Figure 20. Boxplot of deviation of contact point away from strip centre

\subsection{Decoupling vertical and lateral vibration}

In this example, only the vertical and lateral vibrations of carbody are included in the pantograph-catenary interaction separately to investigate the potential decoupling of the spatial vibration. Figure 21 shows the time histories of carbody motion with level 6 of track quality, including the lateral displacement, vertical displacement, roll, pitch and yaw of the carbody. In this numerical example, three scenarios of the simulation are performed. In the first one, all the carbody motions are included in the pantographcatenary interaction. The second and third ones only consider the lateral and vertical vibrations of the carbody, respectively. Figure 22 shows the comparison of the contact force between the vertical excitation and 6-DOF excitation. A slight difference can be observed between the two scenarios. The difference of contact force peak reaches $2.5 \mathrm{~N}$. Figure 23 shows the comparison of absolute contact point deviation between the lateral excitation and 6-DOF excitation. To facilitate the comparison of the maximum deviation of the contact point away from the strip centre, the absolute value of the lateral contact position is presented. It is seen that 6-DOF excitation causes a bigger deviation of the contact point compared with the result with only lateral excitation. 


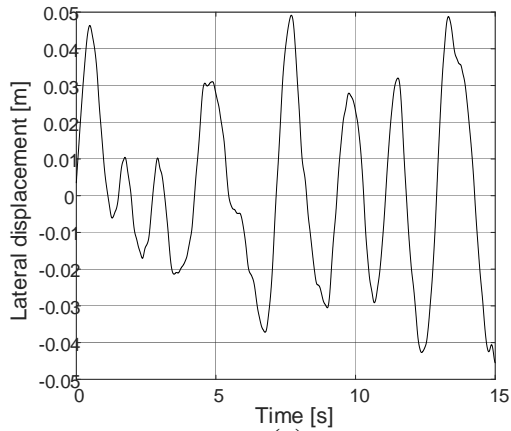

(a)

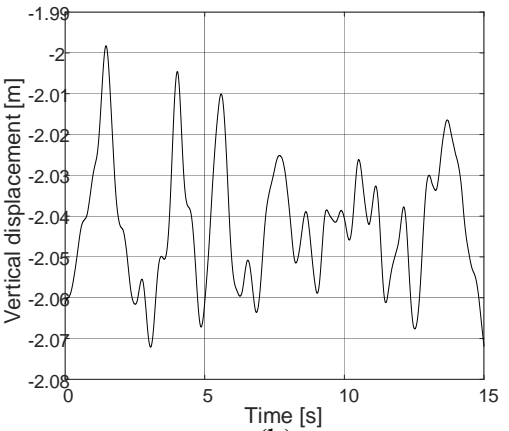

(b)

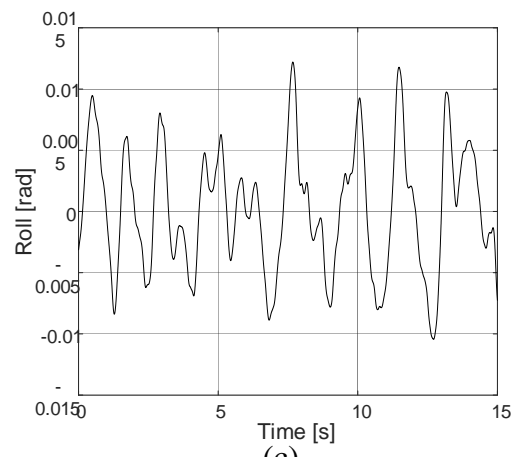

(c)

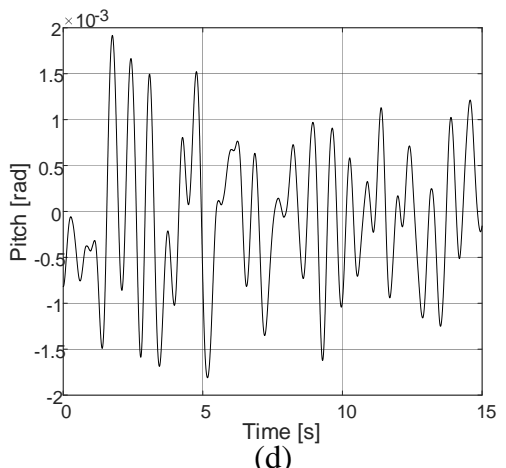

(d)

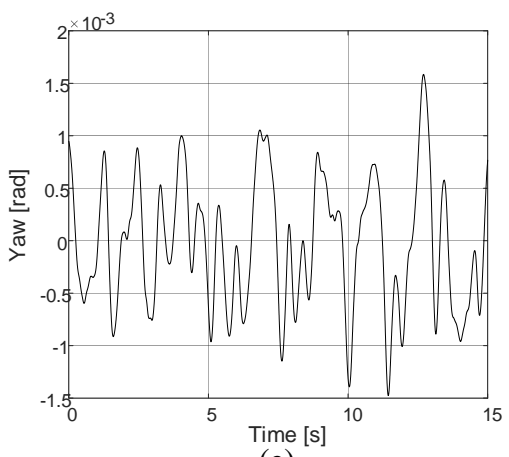

(e)

Figure 21. Time histories of carbody motion with level 6 of track quality

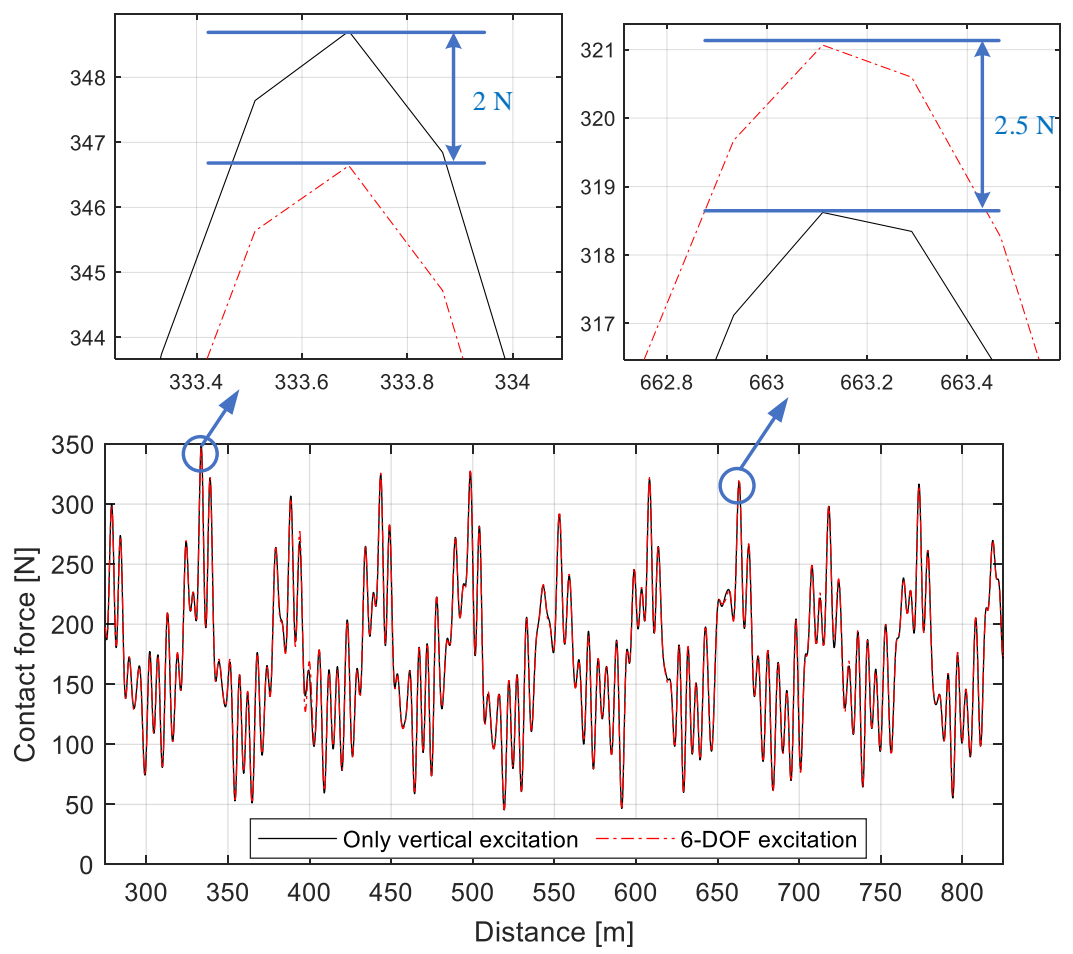

Figure 22. Comparison of contact force between vertical excitation and 6-DOF excitation 


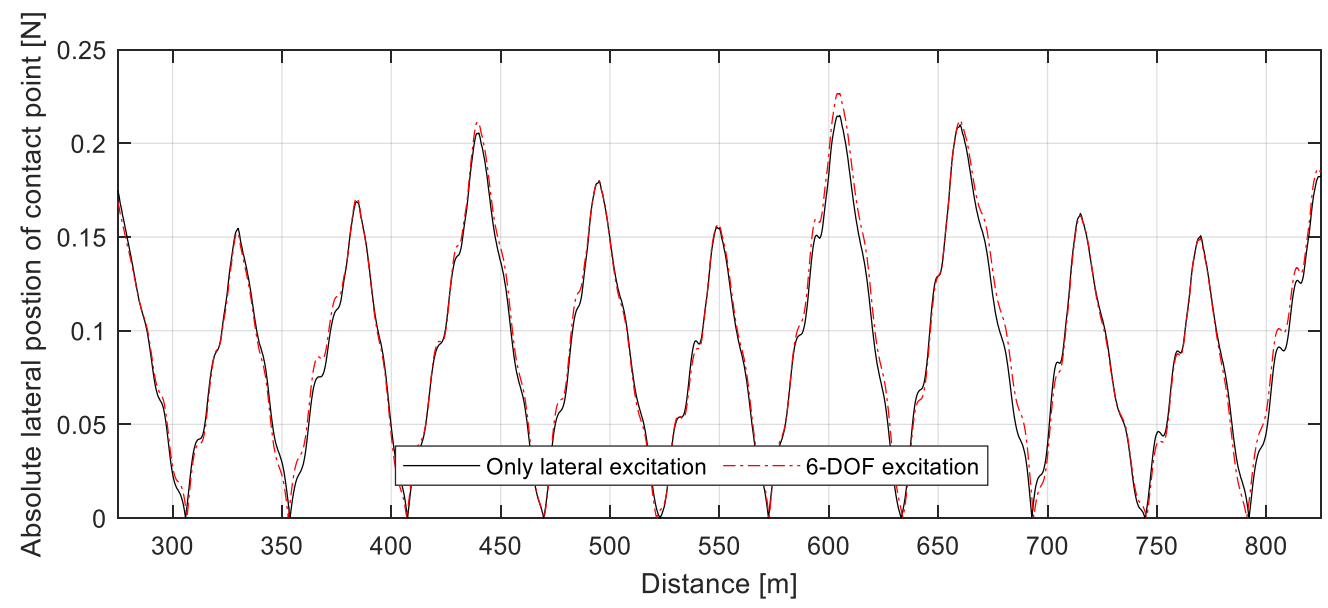

Figure 23. Comparison of absolute lateral contact position between lateral excitation and 6-DOF excitation

Through the above analysis, it is demonstrated that due to the rotation of the carbody, the lateral and vertical vibrations of the pantograph are coupled. A slight error can be generated if the lateral and vertical vibrations are calculated separately.

\section{Application example with realistic case}

In this section, the proposed model is used to evaluate the dynamic performance of a realistic pantograph-catenary system from China high-speed network, with measured rail irregularities. The catenary parameters from Beijing-Tianjin passenger special railway are adopted to construct the catenary model as shown in Figure 24, in which, the overlaps, variances of span length and dropper intervals, in reality, are fully considered. The pantograph model is built using the parameters of DSA 380 pantograph. The vehicletrack system is constructed using the realistic parameters from the specific high-speed network. The measured rail irregularities shown in Figure 25 are adopted to simulate the excitation of the vehicle-track.

In the numerical simulations, the train speeds are defined as the operation speed $300 \mathrm{~km} / \mathrm{h}$, the maximum design speed $350 \mathrm{~km} / \mathrm{h}$ and the potential upgrade speed $380 \mathrm{~km} / \mathrm{h}$. The resulting contact forces evaluated with and without vehicle vibrations are compared. 
The contact force time histories are shown in Figure 26, and the corresponding statistics are shown in Figure 27. As the train is running on a high-quality high-speed track, the effect of the vehicle-track vibration on the pantograph-catenary interaction is very small. The vehicle-track only contribute a bit variance to the contact force. The pantographcatenary system shows a very good performance with the operation speed $300 \mathrm{~km} / \mathrm{h}$ and the design speed $350 \mathrm{~km} / \mathrm{h}$. The statistical minimal contact force is lower than the specified safety threshold with the potential upgrade speed $380 \mathrm{~km} / \mathrm{h}$. The further optimisation strategy is necessary for the speed upgrade.

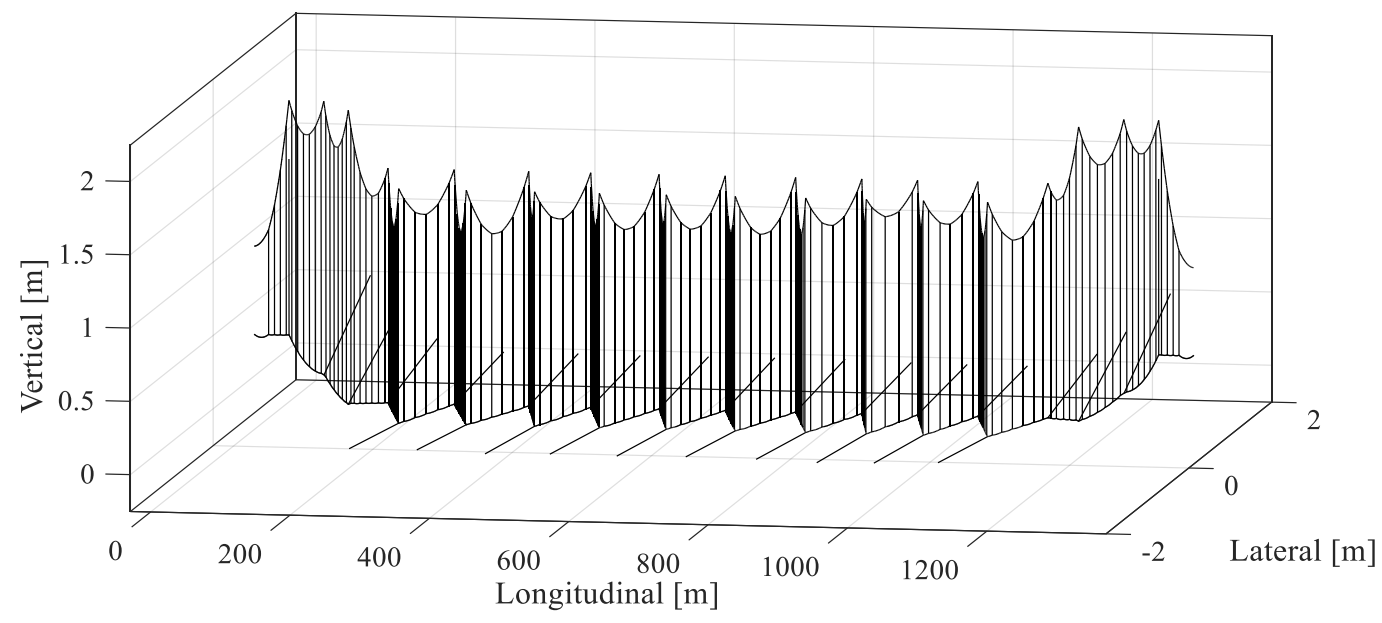

Figure 24. Geometry of realistic catenary

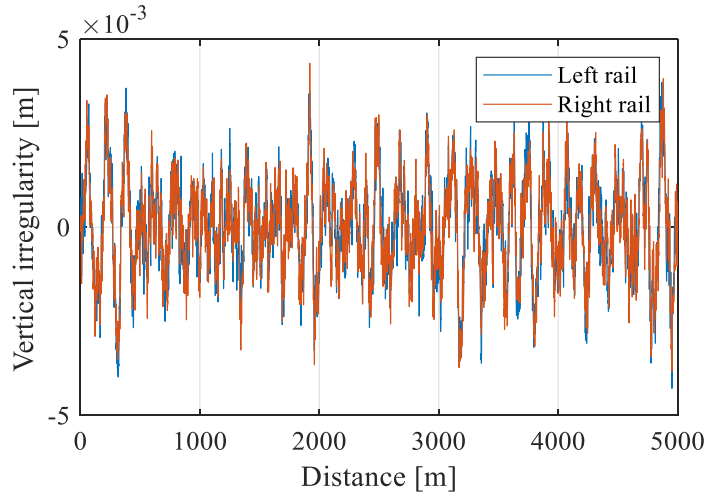

(a)

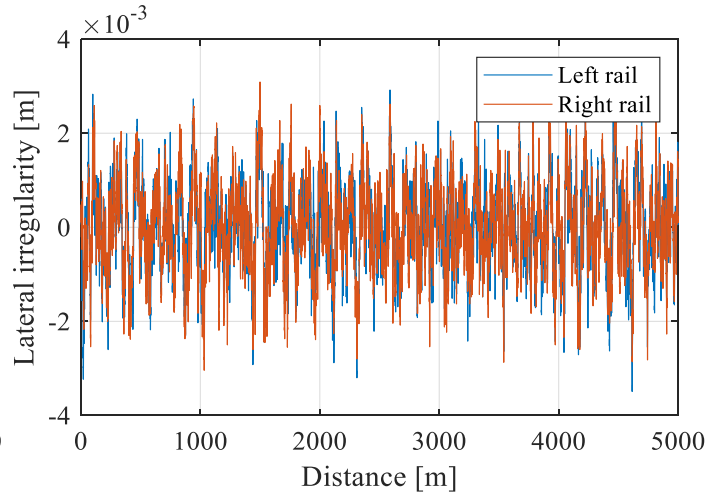

(b)

Figure 25. Realistic measurement data of vertical rail irregularities (a) and lateral rail irregularities (b) 


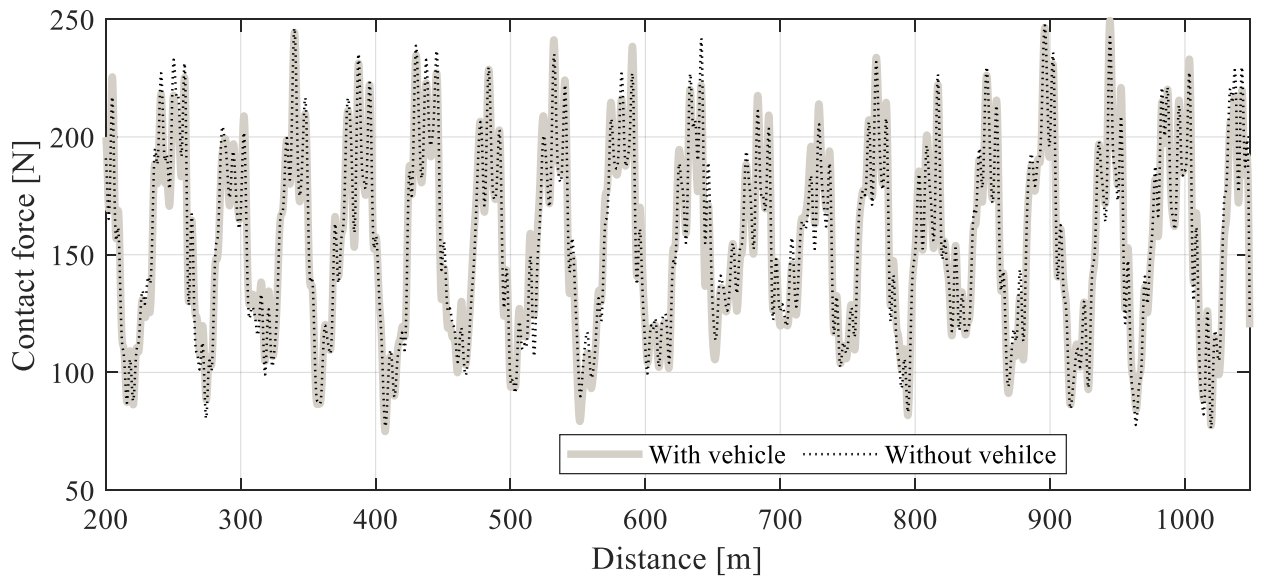

(a)

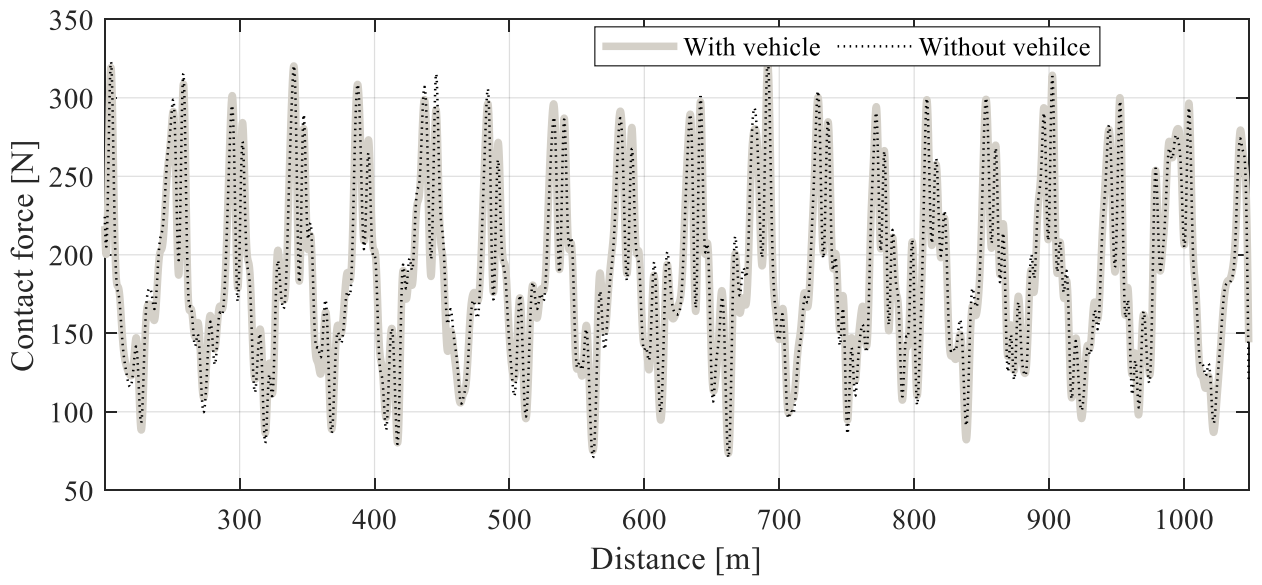

(b)

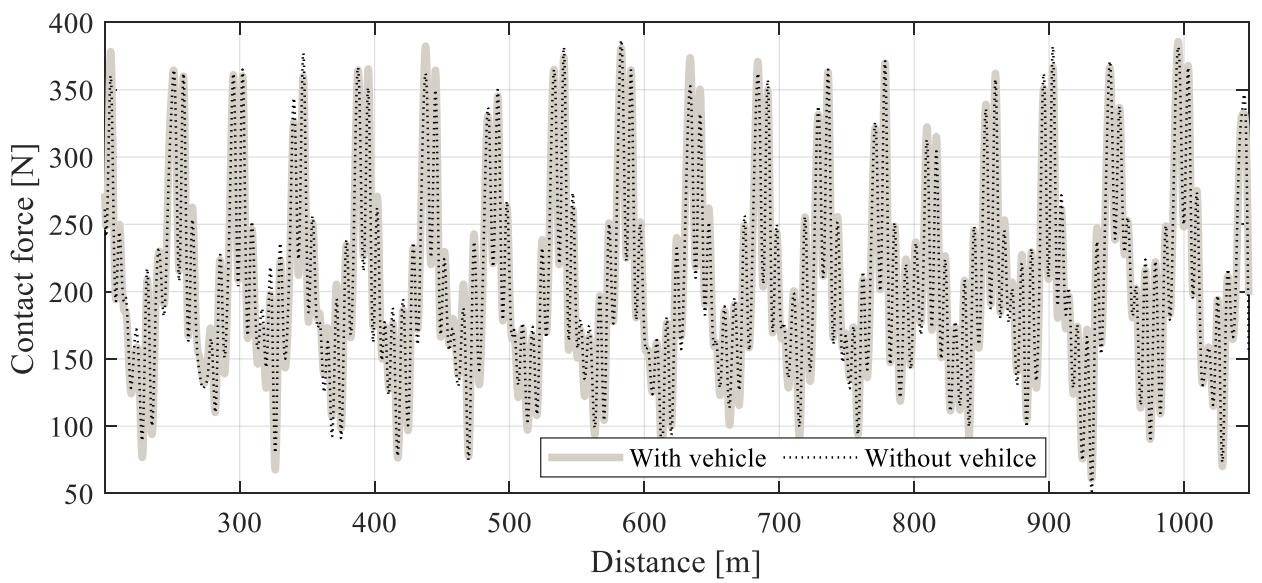

(c)

Figure 26. Results of contact force with $300 \mathrm{~km} / \mathrm{h}(\mathrm{a}), 350 \mathrm{~km} / \mathrm{h}(\mathrm{b})$ and $380 \mathrm{~km} / \mathrm{h}(\mathrm{c})$

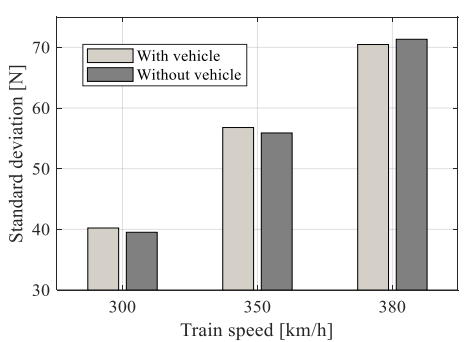

(a)

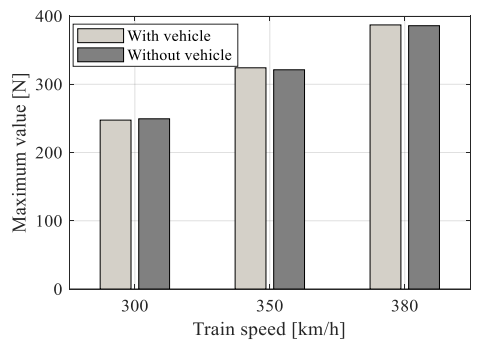

(b)

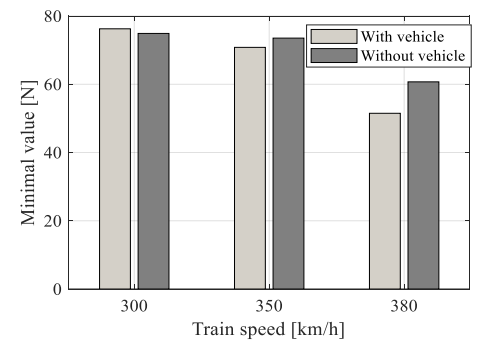

(c) 


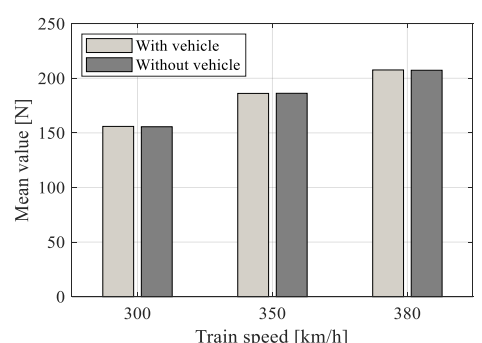

(d)

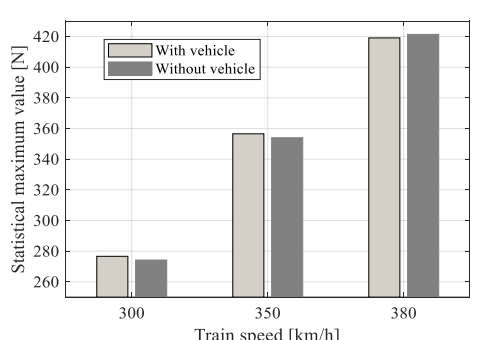

(e)

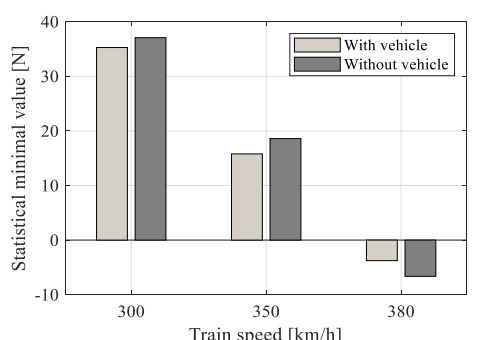

(f)

Figure 27. Statistics of contact force: standard deviation (a); maximum value (b); minimal value (c); mean value (d); statistical maximum value (e); statistical minimal value (f)

\section{Conclusions and future works}

This paper attempts to realise the spatial coupling between the pantograph-catenary system and the vehicle-track system. The carbody vibration is properly added to the base motion of the pantograph. Through the statistical analysis, stochastic analysis and PSD analysis, the dynamic performance of the pantograph-catenary is evaluated with six levels of rail irregularities. The results show that the effect of the rail irregularity on the pantograph-catenary interaction is very complicated, due to its significantly random characteristics. The rail irregularity increases the fluctuation range of the contact force variance, causing the increase of the statistical maximum values, and the decrease of the statistical minimal values. The reliability of the pantograph-catenary system shows a continuous decline with the degradation of the rail quality. The carbody vibration also increases the deviation of the contact point away from the strip centre, which may increase the risk of de-wirement. Furthermore, an application example is present to evaluate the dynamic performance of the pantograph-catenary system running on the China high-speed network with realistic rail irregularities.

However, apart from the rail irregularities, the wind load is another normal source to the carbody vibration. Due to the long-span structure and high flexibility, the catenary is also very sensitive to the wind load. So the effect of wind load on both of the 
pantograph-catenary and the vehicle-track will be considered in the future, to evaluate the dynamic performance of pantograph-catenary in extreme work conditions.

\section{Acknowledgement}

This work was supported in part by the National Natural Science Foundation of China (U1734202).

\section{References}

[1] S. Bruni, G. Bucca, M. Carnevale, A. Collina, A. Facchinetti, Pantograph-catenary interaction: recent achievements and future research challenges, Int. J. Rail Transp. 6 (2018) 57-82. https://doi.org/10.1080/23248378.2017.1400156.

[2] W.H. Zhang, The development of China's high-speed railway systems and a study of the dynamics of coupled systems in high-speed trains, Proc. Inst. Mech. Eng. Part F J. Rail Rapid Transit. $228 \quad$ (2014) 367-377. https://doi.org/10.1177/0954409713478528.

[3] S. Muñoz, J.F. Aceituno, P. Urda, J.L. Escalona, Multibody model of railway vehicles with weakly coupled vertical and lateral dynamics, Mech. Syst. Signal Process. 115 (2019) 570-592. https://doi.org/10.1016/j.ymssp.2018.06.019.

[4] K. Huang, Z. Liu, D. Su, Z. Zheng, A traction network chain-circuit model with detailed consideration of integrated grounding system in tunnel path, IEEE Trans. Transp. Electrif. 5 (2019) 535-551. https://doi.org/10.1109/TTE.2019.2914417.

[5] A. Hada, K. Soga, R. Liu, I.J. Wassell, Lagrangian heuristic method for the wireless sensor network design problem in railway structural health monitoring, Mech. Syst. Signal Process. $28 \quad$ (2012) 20-35. https://doi.org/10.1016/j.ymssp.2011.05.020.

[6] Y. Song, Z. Liu, H. Wang, J. Zhang, X. Lu, F. Duan, Analysis of the galloping 
behaviour of an electrified railway overhead contact line using the non-linear finite element method, Proc. Inst. Mech. Eng. Part F J. Rail Rapid Transit. 232 (2018) 2339-2352. https://doi.org/10.1177/0954409718769751.

[7] A. De Rosa, S. Alfi, S. Bruni, Estimation of lateral and cross alignment in a railway track based on vehicle dynamics measurements, Mech. Syst. Signal Process. 116 (2019) 606-623. https://doi.org/10.1016/j.ymssp.2018.06.041.

[8] M. Bocciolone, G. Bucca, A. Collina, L. Comolli, Pantograph-catenary monitoring by means of fibre Bragg grating sensors: Results from tests in an underground line, Mech. Syst. Signal Process. $41 \quad$ (2013) 226-238. https://doi.org/10.1016/j.ymssp.2013.06.030.

[9] Z. Sun, H. Dai, H. Gao, T. Li, C. Song, Dynamic performance of high-speed train passing windbreak breach under unsteady crosswind, Veh. Syst. Dyn. 57 (2019) 408-424. https://doi.org/10.1080/00423114.2018.1469777.

[10] K. Huang, Z. Liu, F. Zhu, Z. Zheng, Y. Cheng, Evaluation Scheme for EMI of Train Body Voltage Fluctuation on the BCU Speed Sensor Measurement, IEEE Trans. $\quad$ Instrum. $\quad$ Meas. $66 \quad$ (2017) 1046-1057. https://doi.org/10.1109/TIM.2017.2663522.

[11] M. Zhang, F. Xu, Y. Han, Assessment of wind-induced nonlinear post-critical performance of bridge decks, J. Wind Eng. Ind. Aerodyn. (2020). https://doi.org/10.1016/j.jweia.2020.104251.

[12] H.P. Wan, Y.Q. Ni, An efficient approach for dynamic global sensitivity analysis of stochastic train-track-bridge system, Mech. Syst. Signal Process. 117 (2019) 843-861. https://doi.org/10.1016/j.ymssp.2018.08.018.

[13] Z. Liu, Y. Song, Y. Han, H. Wang, J. Zhang, Z. Han, Advances of research on high-speed railway catenary, J. Mod. Transp. $26 \quad$ (2018) 1-23. 
https://doi.org/10.1007/s40534-017-0148-4.

[14] Y. Song, Z. Liu, X. Lu, Dynamic Performance of High-Speed Railway Overhead Contact Line Interacting with Pantograph Considering Local Dropper Defect, IEEE Trans. Veh. Technol. $69 \quad$ (2020) 5958-5967. https://doi.org/10.1109/TVT.2020.2984060.

[15] Y. Song, Z. Liu, A. Rønnquist, P. Nåvik, Z. Liu, Contact Wire Irregularity Stochastics and Effect on High-Speed Railway Pantograph-Catenary Interactions, IEEE Trans. Instrum. Meas. $69 \quad$ (2020) 8196-8206. https://doi.org/10.1109/TIM.2020.2987457.

[16] Y. Song, Z. Liu, F. Duan, X. Lu, H. Wang, Study on wind-induced vibration behavior of railway catenary in spatial stochastic wind field based on nonlinear finite element procedure, J. Vib. Acoust. Trans. ASME. 140 (2018) 011010-1-14. https://doi.org/10.1115/1.4037521.

[17] C. Sanchez-Rebollo, E. Velez, J.R. Jimenez-Octavio, Numerical characterization of real railway overhead cables, Wind Struct. An Int. J. 21 (2015) 105-117. https://doi.org/10.12989/was.2015.21.1.105.

[18] X. Hong, J. Zhou, Y. He, Damage detection of anchored region on the messenger cable based on matching pursuit algorithm, Mech. Syst. Signal Process. 130 (2019) 221-247. https://doi.org/10.1016/j.ymssp.2019.04.053.

[19] S. Pil Jung, Y. Guk Kim, J. Sung Paik, T. Won Park, Estimation of dynamic contact force between a pantograph and catenary using the finite element method, J. Comput. Nonlinear Dyn. 7 (2012) 041006. https://doi.org/10.1115/1.4006733.

[20] S. Daocharoenporn, M. Mongkolwongrojn, S. Kulkarni, A.A. Shabana, Prediction of the pantograph/catenary wear using nonlinear multibody system dynamic algorithms, J. Tribol. 141 (2019) 051603. https://doi.org/10.1115/1.4042658. 
[21] G. Bucca, A. Collina, A procedure for the wear prediction of collector strip and contact wire in pantograph-catenary system, Wear. 266 (2009) 46-59. https://doi.org/10.1016/j.wear.2008.05.006.

[22] S. Bruni, J. Ambrosio, A. Carnicero, Y.H. Cho, L. Finner, M. Ikeda, S.Y. Kwon, J.P. Massat, S. Stichel, M. Tur, W. Zhang, The results of the pantograph-catenary interaction benchmark, Veh. Syst. Dyn. 53 (2015) 412-435. https://doi.org/10.1080/00423114.2014.953183.

[23] O. Lopez-Garcia, A. Carnicero, J.L. Maroño, Influence of stiffness and contact modelling on catenary-pantograph system dynamics, J. Sound Vib. 299 (2007) 806-821. https://doi.org/10.1016/j.jsv.2006.07.018.

[24] S. Sorrentino, D. Anastasio, A. Fasana, S. Marchesiello, Distributed parameter and finite element models for wave propagation in railway contact lines, J. Sound Vib. 410 (2017) 1-18. https://doi.org/10.1016/j.jsv.2017.08.008.

[25] Y. Song, H. Ouyang, Z. Liu, G. Mei, H. Wang, X. Lu, Active control of contact force for high-speed railway pantograph-catenary based on multi-body pantograph model, Mech. Mach. Theory. $115 \quad$ (2017) 35-59. https://doi.org/10.1016/j.mechmachtheory.2017.04.014.

[26] J. Ambrósio, F. Rauter, J. Pombo, M.S. Pereira, A flexible multibody pantograph model for the analysis of the catenary-pantograph contact, Comput. Methods Appl. Sci. 23 (2011) 1-27. https://doi.org/10.1007/978-90-481-9971-6_1.

[27] A. Bautista, J. Montesinos, P. Pintado, Dynamic interaction between pantograph and rigid overhead lines using a coupled FEM - Multibody procedure, Mech. $\begin{array}{llll}\text { Mach. } & \text { Theory. } & 97 & \text { (2016) }\end{array}$ https://doi.org/10.1016/j.mechmachtheory.2015.10.009.

[28] Y. Song, A. Rannquist, P. Navik, Assessment of the High-frequency Response in 
the Railway Pantograph-Catenary Interaction Based on Numerical Simulation, IEEE Trans. Veh. Technol. $9545 \quad$ (2020) 1-1. https://doi.org/10.1109/tvt.2020.3015044.

[29] J.R. Jimenez-Octavio, A. Carnicero, C. Sanchez-Rebollo, M. Such, A moving mesh method to deal with cable structures subjected to moving loads and its application to the catenary-pantograph dynamic interaction, J. Sound Vib. 349 (2015) 216-229. https://doi.org/10.1016/j.jsv.2015.03.051.

[30] Y. Song, Z. Liu, Z. Xu, J. Zhang, Developed moving mesh method for high-speed railway pantograph-catenary interaction based on nonlinear finite element $\begin{array}{llllll}\text { procedure, Int. J. } & \text { Rail } & \text { Transp. } & 7 & \text { (2019) } & \text { 173-190. }\end{array}$ https://doi.org/10.1080/23248378.2018.1532330.

[31] D. Anastasio, A. Fasana, L. Garibaldi, S. Marchesiello, Analytical investigation of railway overhead contact wire dynamics and comparison with experimental results, Mech. Syst. Signal Process. $116 \quad$ (2019) 277-292. https://doi.org/10.1016/j.ymssp.2018.06.021.

[32] D. Zou, W.H. Zhang, R.P. Li, N. Zhou, G.M. Mei, Determining damping characteristics of railway-overhead-wire system for finite-element analysis, Veh. Syst. Dyn. 54 (2016) 902-917. https://doi.org/10.1080/00423114.2016.1172715.

[33] A. Facchinetti, S. Bruni, Hardware-in-the-loop hybrid simulation of pantographcatenary interaction, J. Sound Vib. 331 (2012) 2783-2797. https://doi.org/10.1016/j.jsv.2012.01.033.

[34] P. Nåvik, A. Rønnquist, S. Stichel, Variation in predicting pantograph-catenary interaction contact forces, numerical simulations and field measurements, Veh. $\begin{array}{llll}\text { Syst. } & \text { Dyn. } & 55 & \text { (2017) }\end{array}$ https://doi.org/10.1080/00423114.2017.1308523. 
[35] J.H. Lee, T.W. Park, H.K. Oh, Y.G. Kim, Analysis of dynamic interaction between catenary and pantograph with experimental verification and performance evaluation in new high-speed line, Veh. Syst. Dyn. 53 (2015) 1117-1134. https://doi.org/10.1080/00423114.2015.1025797.

[36] H. Wang, Z. Liu, A. Núñez, R. Dollevoet, Entropy-Based Local Irregularity Detection for High-Speed Railway Catenaries with Frequent Inspections, IEEE $\begin{array}{lllll}\text { Trans. } & \text { Instrum. } & \text { Meas. } & 68 & \text { (2019) }\end{array}$ https://doi.org/10.1109/TIM.2018.2881529.

[37] P. Nåvik, A. Rønnquist, S. Stichel, The use of dynamic response to evaluate and improve the optimization of existing soft railway catenary systems for higher speeds, Proc. Inst. Mech. Eng. Part F J. Rail Rapid Transit. 230 (2015) 1388-1396. https://doi.org/10.1177/0954409715605140.

[38] Z. Xu, Y. Song, Z. Liu, Effective Measures to Improve Current Collection Quality for Double Pantographs and Catenary Based on Wave Propagation Analysis, IEEE $\begin{array}{lllll}\text { Trans. } & \text { Veh. } & \text { Technol. } & 69 & \text { (2020) }\end{array}$ https://doi.org/10.1109/TVT.2020.2985382.

[39] J. Pombo, J. Ambrósio, M. Pereira, Influence of pantograph components on the contact quality of the overhead system for high speed trains, Civil-Comp Proc. 93 (2010). https://doi.org/10.4203/ccp.93.1.

[40] W. Wang, Y. Liang, W. Zhang, S. Iwnicki, Effect of the nonlinear displacementdependent characteristics of a hydraulic damper on high-speed rail pantograph dynamics, Nonlinear Dyn. 95 (2019) 3439-3464. https://doi.org/10.1007/s11071019-04766-4.

[41] P. Zdziebko, A. Martowicz, T. Uhl, An investigation on the active control strategy for a high-speed pantograph using co-simulations, Proc. Inst. Mech. Eng. Part I J. 
Syst. Control Eng. $233 \quad$ (2019) 370-383. https://doi.org/10.1177/0959651818783645.

[42] C. Sanchez-Rebollo, J.R. Jimenez-Octavio, A. Carnicero, Active control strategy on a catenary-pantograph validated model, Veh. Syst. Dyn. 51 (2013) 554-569. https://doi.org/10.1080/00423114.2013.764455.

[43] Y. Song, Z. Liu, H. Ouyang, H. Wang, X. Lu, Sliding Mode Control with PD Sliding Surface for High-Speed Railway Pantograph-Catenary Contact Force under Strong Stochastic Wind Field, Shock Vib. 2017 (2017) 4895321-1-16. https://doi.org/10.1155/2017/4895321.

[44] X. Lu, Z. Liu, Y. Song, H. Wang, J. Zhang, Y. Wang, Estimator-based multiobjective robust control strategy for an active pantograph in high-speed railways, Proc. Inst. Mech. Eng. Part F J. Rail Rapid Transit. 232 (2018) 10641077. https://doi.org/10.1177/0954409717707399.

[45] Y. Song, Z. Liu, F. Duan, Z. Xu, X. Lu, Wave propagation analysis in high-speed railway catenary system subjected to a moving pantograph, Appl. Math. Model. 59 (2018) 20-38. https://doi.org/10.1016/j.apm.2018.01.001.

[46] S. Gregori, M. Tur, E. Nadal, F.J. Fuenmayor, An approach to geometric optimisation of railway catenaries, Veh. Syst. Dyn. 56 (2018) 1162-1186. https://doi.org/10.1080/00423114.2017.1407434.

[47] J. Pombo, J. Ambrosio, M. Pereira, F. Rauter, A. Collina, A. Facchinetti, Influence of the aerodynamic forces on the pantograph-catenary system for high-speed trains, Veh. Syst. Dyn. $47 \quad$ (2009) 1327-1347. https://doi.org/10.1080/00423110802613402.

[48] Y. Song, Z. Liu, H. Wang, X. Lu, J. Zhang, Nonlinear analysis of wind-induced vibration of high-speed railway catenary and its influence on pantograph-catenary 
interaction, Veh. Syst. Dyn. $54 \quad$ (2016) 723-747. https://doi.org/10.1080/00423114.2016.1156134.

[49] M. Carnevale, A. Facchinetti, L. Maggiori, D. Rocchi, Computational fluid dynamics as a means of assessing the influence of aerodynamic forces on the mean contact force acting on a pantograph, Proc. Inst. Mech. Eng. Part F J. Rail Rapid Transit. 230 (2016) 1698-1713. https://doi.org/10.1177/0954409715606748.

[50] M. Bocciolone, F. Resta, D. Rocchi, A. Tosi, A. Collina, Pantograph aerodynamic effects on the pantograph-catenary interaction, Veh. Syst. Dyn. 44 (2006) 560570. https://doi.org/10.1080/00423110600875484.

[51] M. Carnevale, A. Facchinetti, D. Rocchi, Procedure to assess the role of railway pantograph components in generating the aerodynamic uplift, J. Wind Eng. Ind. Aerodyn. 160 (2017) 16-29. https://doi.org/10.1016/j.jweia.2016.11.003.

[52] W.M. Zhai, C.B. Cai, Effect of locomotive vibrations on pantograph-catenary system dynamics, Veh. Syst. Dyn. $29 \quad$ (1998) 47-58. https://doi.org/10.1080/00423119808969551.

[53] A. Carnicero, J.R. Jimenez-Octavio, C. Sanchez-Rebollo, A. Ramos, M. Such, Influence of track irregularities in the catenary-pantograph dynamic interaction, J. Comput. Nonlinear Dyn. 7 (2012) 041015. https://doi.org/10.1115/1.4006735.

[54] L. Xu, W. Zhai, A model for vehicle-track random interactions on effects of crosswinds and track irregularities, Veh. Syst. Dyn. 57 (2019) 444-469. https://doi.org/10.1080/00423114.2018.1469775.

[55] T. Zhang, Z. Chen, W. Zhai, K. Wang, Establishment and validation of a locomotive-track coupled spatial dynamics model considering dynamic effect of gear transmissions, Mech. Syst. Signal Process. 119 (2019) 328-345. https://doi.org/10.1016/j.ymssp.2018.09.032. 
[56] P. Mercorelli, A denoising procedure using wavelet packets for instantaneous detection of pantograph oscillations, Mech. Syst. Signal Process. 35 (2013) 137149. https://doi.org/10.1016/j.ymssp.2012.09.001.

[57] W. Zhai, Vehicle-Track Coupled Dynamics, Springer Singapore, 2020. https://doi.org/10.1007/978-981-32-9283-3.

[58] Z. Wang, W. Zhang, Z. Yin, Y. Cheng, G. Huang, H. Zou, Effect of vehicle vibration environment of high-speed train on dynamic performance of axle box bearing, Veh. Syst. Dyn. $57 \quad$ (2019) 543-563. https://doi.org/10.1080/00423114.2018.1473615.

[59] S. Strano, M. Terzo, On the real-time estimation of the wheel-rail contact force by means of a new nonlinear estimator design model, Mech. Syst. Signal Process. 105 (2018) 391-403. https://doi.org/10.1016/j.ymssp.2017.12.024.

[60] Z. Wang, G. Mei, Q. Xiong, Z. Yin, W. Zhang, Motor car-track spatial coupled dynamics model of a high-speed train with traction transmission systems, Mech. $\begin{array}{llll}\text { Mach. } & \text { Theory. } & & \text { 386-403 }\end{array}$ https://doi.org/10.1016/j.mechmachtheory.2019.03.032.

[61] Y. Song, Z. Liu, H. Wang, X. Lu, J. Zhang, Nonlinear modelling of high-speed catenary based on analytical expressions of cable and truss elements, Veh. Syst. Dyn. 53 (2015) 1455-1479. https://doi.org/10.1080/00423114.2015.1051548.

[62] K.S. Kim, H.S. Lee, Analysis of target configurations under dead loads for cablesupported bridges, Comput. Struct. $79 \quad$ (2001) 2681-2692. https://doi.org/10.1016/S0045-7949(01)00120-1.

[63] G. Bucca, A. Collina, Electromechanical interaction between carbon-based pantograph strip and copper contact wire: A heuristic wear model, Tribol. Int. 92 (2015) 47-56. https://doi.org/10.1016/j.triboint.2015.05.019. 
[64] P. Antunes, J. Ambrósio, J. Pombo, A. Facchinetti, A new methodology to study the pantograph-catenary dynamics in curved railway tracks, Veh. Syst. Dyn. 58 (2020) 425-452. https://doi.org/10.1080/00423114.2019.1583348.

[65] Z. Wang, G. Mei, W. Zhang, Y. Cheng, H. Zou, G. Huang, F. Li, Effects of polygonal wear of wheels on the dynamic performance of the gearbox housing of a high-speed train, Proc. Inst. Mech. Eng. Part F J. Rail Rapid Transit. 232 (2018) 1852-1863. https://doi.org/10.1177/0954409717752998.

[66] M.J. Goodwin, Dynamics of railway vehicle systems, 1987. https://doi.org/10.1016/0378-3804(87)90070-2.

[67] F. Kiessling, R. Puschmann, A. Schmieder, E. Schneider, Contact lines for electric railways, third edition, Third Edit, John Wiley \& Sons, 2018.

[68] Z. Wang, Y. Song, Z. Yin, R. Wang, W. Zhang, Random Response Analysis of Axle-Box Bearing of a High-Speed Train Excited by Crosswinds and Track Irregularities, IEEE Trans. Veh. Technol. 68 (2019) 10607-10617. https://doi.org/10.1109/TVT.2019.2943376. 